\title{
LA SOCIEDAD BALLENERA DE MAGALLANES: DE CAZADORES DE BALLENAS A "HÉROES" QUE MARCARON LA SOBERANÍA NACIONAL, 1906-1916**
}

\begin{abstract}
RESUMEN
El artículo investiga la historia de la Sociedad Ballenera de Magallanes, desde su formación en 1906 hasta su disolución en 1916. Una primera parte está destinada a la descripción de la Sociedad, utilizando fuentes primarias como periódicos de la época de la región de Magallanes y diarios de viaje de exploradores o viajeros extranjeros. La segunda parte reflexiona en torno a los significados de la empresa ballenera en estudio, destacándose su rol económico y geopolítico. Se aborda la ausencia de un concepto de sustentabilidad aplicable a la cacería antártica de la ballena a principios de siglo, fenómeno palpable en el caso de estudio. Finalmente se reflexiona en torno al imaginario de heroicidad presente en la época y en una variada literatura de la segunda mitad del siglo XX, en relación a la cacería de ballenas y específicamente a la Sociedad Ballenera de Magallanes.
\end{abstract}

Palabras clave: historia regional, cacería ballenas, territorio antártico.

\begin{abstract}
The article deals with the history of the Whaling Society of Magallanes since its formation in 1906 until its dissolution in 1916. The first part describes the Society using primary sources including newspapers from Magallanes and travel accounts written by explorers and foreign travelers during the period. The second part reflects on the significance this whaling company had in economic and geopolitical terms. There is consideration of the absence of the idea of a sustainable exploitation of whales in the Antarctic region at the beginning of the Twentieth Century. Finally, the article reflects about the heroic imaginary elaborated during the period and years later in the varied literature about the Whaling Society of Magallanes.
\end{abstract}

Key words: Regional History, Whaling, Antarctic Territory.

Fecha de recepción: agosto de 2009

Fecha de aceptación: enero de 2010

* Doctora en Sociología, Universidad de Essex. Profesora Universidad Academia de Humanismo Cristiano. Correo electrónico: nnicholls@academia.cl

** Este escrito es fruto del proyecto Fondecyt $N^{\circ} 1080115$, titulado "La cacería de ballenas en las costas de Chile: una mirada desde la antropología”, en el cual la autora se desempeña como coinvestigadora. 


\section{LA Sociedad BALlenera DE MAgallanes: "LA MEJOR MONTADA DE LA ZONA"}

\section{La región magallánica: colonización y aventuras empresariales}

Al iniciarse el siglo XX, la región magallánica era una zona próspera, que albergaba variadas actividades económicas de distinta índole. El centro sin embargo de todas las explotaciones y giros industriales regionales era la ganadería lanar. Ello queda de manifiesto si tomamos en cuenta las cifras del comercio de exportación. En el año 1906, el 92\% de las exportaciones regionales correspondía a productos ganaderos, y dentro de ellos, un 75,2\% estaba representado por la lana $^{1}$. Pese al indiscutible peso de la producción ovina, actividades como la minería -aurífera, cuprífera, petrolera y carbonífera- dejaron frutos considerables en la región. Como ha señalado Mateo Martinic, la región gozaba de esplendor en aquella época y esto se hacía evidente en el auge de la actividad mercantil, que a su vez se reflejaba en su comercio exportador y en su capacidad de consumo interno ${ }^{2}$.

Punta Arenas, además de su condición de único puerto de la zona destinado al tráfico de ultramar, recibía inmigrantes europeos, algunos de los cuales llegaban a las tierras australes sin capital alguno, pero sí con las intenciones de alcanzar prosperidad a través de los negocios. Fue el caso, por ejemplo, del español José Menéndez, quien siendo muy joven, logró en el último cuarto del siglo XIX generar una fortuna, iniciándose como comerciante de un negocio ya existente "venido a menos" y terminando como empresario multifacético de considerable riqueza y reconocido prestigio en la ciudad ${ }^{3}$. Algo similar ocurrió con Mauricio Braun, hijo de Elías Braun -de oficio hojalatero- y de Sofía Hamburger, judíos alemanes que llegaron a establecerse en la colonia de Punta Arenas en el año 1874. Mauricio Braun comenzó a los 15 años como dependiente de comercio de José Nogueira, uno de los empresarios pioneros de la región, a quien le venía muy bien para sus negocios el hecho de que Braun hablara y escribiera, además de español, alemán e inglés. De dependiente y tenedor de libros para Nogueira, Braun terminó siendo un empresario próspero tan multifacético como su suegro, José Menéndez -dedicado a los rubros de la explotación ovina, industria naviera, comercio en general y actividad bancaria ${ }^{4}$.

La prosperidad de la zona magallánica, región de "colonizadores", territorio atractivo por su variado potencial de explotación económica, atrajo sin embargo no solo a quienes vieron en los rubros antes mencionados una posibilidad de sustento y enriquecimiento. Las zonas australes del continente americano fueron también un

Mateo Martinic, Historia de la región magallánica, Punta Arenas, Ediciones de la Universidad de Magallanes, 2006, III, 896.

2 Ibid., III, 898.

3 Véase Mateo Martinic, "Las actividades económicas iniciales de José Menéndez 1875-1885", Punta Arenas, Publicaciones de Instituto de la Patagonia, Series Monográficas nº 8, 1975.

4 Nelson Toledo, Patagonia y Antártica. 100 Personajes Históricos, Punta Arenas, La Prensa Austral Impresos, 2006, 33. 
polo de atracción para quienes vislumbraron en su potencial marítimo -y específicamente en la cacería de la ballena- un rubro digno de explotación y desarrollo. Hombres provenientes del Viejo Mundo, avezados en la práctica de la cacería de los cetáceos, abandonaron los fríos mares del hemisferio norte buscando nuevas áreas de explotación ${ }^{5}$. La indiscriminada caza de ballenas en la zona ártica había ocasionado una considerable baja en su número en fechas tan tempranas como el siglo XVIII ${ }^{6}$, por lo cual las regiones australes aparecían como un gran manto no explotado, que podía proporcionar dividendos importantes.

A principios del siglo XX nos encontramos con varios proyectos de sociedades balleneras, algunas centradas en la cacería antártica, otras en el estrecho de Magallanes o más al norte, en Valdivia, e incluso algunas cuyas bases de operaciones se situaban en Valparaíso. Claramente, el propósito de explotar el rubro de la cacería tanto de ballena como del lobo marino estuvo también en la mente de empresarios de la región de Magallanes, dispuestos a arriesgar sus capitales en nuevas empresas que parecían a todas luces rentables. Así por ejemplo, en el año 1902 el gobierno le concedió a Pedro Pablo Benavides el arrendamiento de las islas Diego Ramírez y San Idelfonso, para la explotación de "toda clase de pesca indefinidamente hacia el sur"7. La casa Braun \& Blanchard había realizado un intento aquel mismo año, enviando tres goletas en exploración hacia las islas Shetland del Sur, pero al no otorgar los resultados esperados desistió, al menos temporalmente, de la empresa. Por su parte, los residentes británicos en Punta Arenas James C. Robins y James Docherty, junto a los alemanes Ricardo Lion y Fernando Wlodarowsky, crearon en 1906 la South Georgia Exploration Compañía Limitada, que pese a todo el ímpetu inicial manifestado en viajes de exploración y solicitud de permisos para el arrendamiento de las islas que se pretendía utilizar como bases, entre otras gestiones, no llegó a consolidarse ${ }^{8}$. Aquel mismo año, la Compañía Chilena de Balleneros, cuya fecha de formación desconocemos, obtenía del Ministerio de Hacienda un decreto de autorización de cambio de estatutos, el cual fue aprobado. También en 1906, surgía la Compañía Austral de Pesquería como sociedad anónima, que tenía la finalidad de explotar no solo la

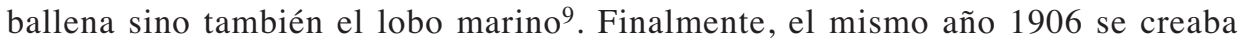
la Sociedad Ballenera y Pescadora de Valdivia, que adquiría la planta ballenera de la Sociedad Klempau, Anwandter i Compañía en Corral, de tal modo de dedicarse "a la pesca de ballena i la pesquería en general i a la compra-venta i elaboración de materias primas correspondientes a su objeto"10.

Paula Contreras, De polo a polo: Historia de la primera inmigración noruega a Chile, Santiago, Editorial Cuarto Propio, 2004, 32.

6 Claudio Campagna y Alfredo Lichter, Las Ballenas de la Patagonia, Buenos Aires, Emecé Editores, 1996, 150 .

7 José Betancourt, Una industria en crisis. Ensayo sobre la industria ballenera, Memoria de Prueba, Pontificia Universidad Católica de Chile, Santiago, 1963, 175.

8 Martinic, Historia..., op . cit., 824-825.

9 Betancourt, op. cit., 175-176.

10 Estatutos de la Sociedad Ballenera y Pescadora Valdivia, Valdivia, Imprenta Comercio, 1907,5 . 
De todos estos proyectos y sociedades, la empresa ballenera chilena más relevante del período, tanto por las implicancias económicas de su explotación como por la ocupación geográfica de territorios escasamente explorados y mucho menos ocupados, fue la Sociedad Ballenera de Magallanes. Formada por decreto supremo en el año 1906, con la firma del presidente Germán Riesco, fue presidida por Mauricio Braun, Pedro de Bruyne como gerente y por el noruego nacionalizado chileno Adolfo A. Andresen, que cumplió el rol de administrador ${ }^{11}$.

Andresen ya se había asociado al empresario Mauricio Braun en 1903, realizando el primer viaje de cacería de la ballena, desde Punta Arenas hasta el cabo de Hornos, el cual tuvo mucho de exploratorio, ya que no se sabía a ciencia cierta cuán fructífera sería la empresa. Si bien el viaje en cuestión no reportó ninguna ballena cazada, Andresen emprendió una nueva aventura ballenera, previo contrato de una tripulación adecuada para las faenas que se proyectaban, en el puerto de Ancud. Esta vez los resultados fueron mejores. Ello movió a los socios a intentar la formación de una empresa con mayores capitales, que facilitara un mejor rendimiento, de modo que se atrajo al proyecto a Pedro A. de Bruyne. La Sociedad en comandita inaugurada se titulaba Sociedad De Bruyne, Andresen y Cía. y fue establecida a fines del año $1904^{12}$, obteniendo los permisos oficiales de parte del gobierno para ocupar Bahía Águila, treinta millas al sur de la ciudad de Punta Arenas, donde se estableció un centro de operaciones para la recién montada compañía. Bahía Águila fue acondicionada con caldera, herrería, tonelería, cocina, varios edificios para fábrica y alojamiento para los trabajadores. Completaba el paisaje un varadero destinado a que los barcos pudieran, mediante cabrestantes, bajar las ballenas cazadas a tierra ${ }^{13}$. La descripción de la infraestructura con la que se dotó la planta de Bahía Águila indica que la empresa se estaba proyectando en el tiempo y que además tenía la capacidad de inversión que hiciera posible mayores ganancias en el futuro. En este primer intento por desarrollar seriamente la cacería de la ballena, Andresen exploró el estrecho de Magallanes, así como mares cercanos a su desembocadura, tanto del Pacífico como del Atlántico.

La iniciativa de Andresen y sus socios fue del todo exitosa, de tal modo que decidieron disolver la recién iniciada sociedad y buscar nuevos capitales que pudieran apoyar un proyecto que a todas luces se veía muy rentable, de manera de emprender la actividad ballenera desde una base mucho más sólida ${ }^{14}$. Fue así como

11 Jorge Sepúlveda, "La epopeya de la industria ballenera chilena", en Revista de Marina 115:841, Valparaíso, 1997 (disponible en www.revistamarina.cl/revistas/1997/6/jorsepul.pdf). Véase también: Sociedad Ballenera de Magallanes, $2^{a}$ Memoria presentada a los señores accionistas en la reunión general de 29 de enero de 1908, Punta Arenas, Imp. y Encuadernación E1 Magallanes, $1908, \mathrm{~s} / \mathrm{n}$.

12 Martinic, Historia..., op. cit., 825-826.

13 Mauricio Braun en sus memorias habla de Bahía Aguirre, pero creemos que es un error, ya que su ubicación coincide con la de Bahía Águila. Además ninguna otra fuente hace mención a Bahía Aguirre, en tanto que hay abundancia de documentos que se refieren a Bahía Águila como planta de la Sociedad Ballenera de Magallanes. Mauricio Braun, Memorias de una vida colmada, Buenos Aires, Gaglianone Establecimiento Gráfico S. A., 1985, 207.

14 Gustavo E. Camelio Rial, La industria pesquera en la zona de Magallanes, Memoria de Prueba para optar al título de Ingeniero Comercial, Pontificia Universidad Católica de Chile, Facultad de Ciencias Económicas y Sociales, Santiago, 1966, 4. 
surgió la Sociedad Ballenera de Magallanes, autorizada por decreto supremo del 7 de julio de $1906^{15}$. Andresen fue sin duda el alma de la empresa. Si seguimos a Alfonso M. Filippi, fue él quien tuvo la visión económica para advertir que una sociedad de este tipo tendría un gran porvenir ${ }^{16}$. Mauricio Braun, presidente y accionista de la sociedad, narró en sus memorias que si bien las ballenas estaban presentes en su imaginario a través de Moby Dick y de los relatos que escuchaba en su calidad de cónsul provenientes de los balleneros norteamericanos que de cuando en cuando recalaban en Punta Arenas, fue Andresen quien logró interesarlo en la empresa de cacería que hasta ese momento no le había parecido digna de explotar ${ }^{17}$. Fue Andresen también quien recorrió los mares desde Noruega hacia Chile y desde Chile hacia Noruega, cada vez que fue necesario en la etapa de preparación de la compañía. Contaba además con la experiencia y el conocimiento en la moderna cacería de ballenas; él zarparía en el futuro con la flotilla por las inhóspitas aguas antárticas demostrando confianza y experiencia, además de un dominio técnico para la empresa que llevaba a cabo. De hecho, en la Segunda Memoria de la Sociedad Ballenera de Magallanes, presentada a los accionistas con fecha 29 de enero del año 1908, es decir después de aproximadamente un año y medio de funcionamiento de la compañía, se declaraba:

"Al directorio le es grato dejar constancia que el personal bajo las órdenes del administrador, Capitán A. Andresen, ha dado durante toda la faena la mas completa satisfacción y que principalmente debemos al buen criterio i actividad desplegados por dicho señor administrador el resultado obtenido" 18 .

Su nombre finalmente es el que resuena al hablar de la Sociedad Ballenera de Magallanes. Andresen supo asociarse a los empresarios más destacados de la región para asegurar la viabilidad y continuidad de su empresa. En el año 1908, el directorio de la sociedad estaba formado por Mauricio Braun como presidente, Alejandro Menéndez como vicepresidente, P. Van Peborgh y F. Willumsen como directores, P. A. de Bruyne como director gerente y el propio Andresen como administrador ${ }^{19}$. Mauricio Braun era, en efecto, armador y comerciante, socio de la casa Braun \& Blanchard, "la más progresista casa armatorial de Punta Arenas", al mismo tiempo que “es el empresario con más empuje y visión en Magallanes y el que goza de mayor fama por su interés en toda actividad económica que sea novedosa" ${ }^{20}$. La lista de

15 Sociedad Ballenera de Magallanes, op. cit.

16 Alfonso M. Filippi, "El comodoro Andresen y la actividad ballenera austral y antártica chilena”, en Revista Marina 1997:3, Valparaíso, 1997, 2.

17 Braun, Memoria..., op. cit., 207.

18 Sociedad Ballenera de Magallanes, op. cit.

19 Idem.

20 Filippi, op. cit., 2. Mateo Martinic, en su libro Menéndez y Braun. Prohombres Patagónicos, traza la trayectoria de estos dos empresarios magallánicos a principios del siglo $\mathrm{XX}$, demostrando su gran versatilidad que los llevó a desarrollar los más variados negocios. Sus capitales estaban puestos en la actividad pastoril, en los derivados de la ganadería ovina, en el cabotaje marítimo y en la minería, entre varios otros. Dichas iniciativas empresariales, sobre todo en lo que concierne a Mauricio Braun, fueron decisivas en el proceso colonizador de la región. Véase Mateo Martinic, Menéndez y Braun. Prohombres Patagónicos, Punta Arenas, Ediciones de la Universidad de Magallanes, 2001. 
accionistas contemplaba además nombres como el de José Menéndez Behety, hijo de José Menéndez, e instituciones como el Banco Anglo Sud Americano. Fueron Mauricio Braun y José Menéndez quienes aportaron el grueso del capital inicial de la sociedad, que consistió en 100 mil pesos ${ }^{21}$. En suma, los dos grandes grupos económicos que formaban lo que Martinic denomina "el oligopolio económico magallánico" 22 de la época, esto es, los Braun Hamburger y los Menéndez Behety, participaban de la Sociedad Ballenera de Magallanes.

\section{El montaje de la flota: todos los elementos para una "cacería moderna"}

Una buena flota era fundamental para una empresa que proyectaba montarse a gran escala; del número de buques cazadores con que contaba una sociedad ballenera dependía en gran medida el volumen de ballenas cazadas, como lo deja ver el prospecto de otra compañía que por la misma época actuaba en Valdivia. La sociedad en cuestión, denominada Sociedad Ballenera y Pescadora Valdivia, solo poseía un barco cazador en el año 1907, denominado Germania, que debía actuar además como remolcador. El prospecto de crecimiento de la sociedad planteaba la necesidad de operar con dos buques cazadores que se dedicaran exclusivamente a la caza y con un remolcador que se concentrara en su rol de tal y que pudiera así trasladar de 15 a 20 ballenas a la vez a las plantas con las que contaba la empresa. De esa manera, "se subsanarían muchos inconvenientes"23.

En el año 1909, la Sociedad Ballenera de Magallanes estaba compuesta por los siguientes navíos: Gobernador Bories, Almirante Montt, Almirante Valenzuela, Almirante Uribe y velero Cornelia Jacoba ${ }^{24}$. Más tarde adquiriría el Almirante Señoret y el Almirante Goñi ${ }^{25}$.

El Gobernador Bories era un buque factoría, el buque-madre como lo denominaba Braun, construido específicamente para la tarea que desempeñaría en los mares del Sur. El Almirante Montt, un buque cazador, había sido mandado a construir en 1905 por la Sociedad De Bruyne, Andresen y Compañía, siendo Andresen designado por sus socios capitalistas para cumplir la misión de adquirir en Noruega, su país natal, tanto el buque como los implementos necesarios para su primera aventura ballenera ${ }^{26}$. El Almirante Valenzuela y el Almirante Uribe completaban la dotación de buques cazadores o catchers, en tanto el Cornelia Jacoba actuaba como pontón, es decir como navío para depósito de carbón y almacenamiento de aceite. Los catchers dependían del gran buque factoría, que

21 Jaime Eyzaguirre, La soberanía de Chile en las tierras australes, Santiago, Editorial Zig-Zag, $1958,51$.

22 Véase Martinic, Historia..., op. cit., 907-912.

23 Sociedad Ballenera y Pescadora Valdivia, Prospecto, Valdivia, Imprenta Central, J. Lampert, 1907, 4.

24 Chile Austral, Punta Arenas, 18 de marzo de 1909, 6.

25 Martinic señala que para la campaña de caza de 1912-1913, que fue del todo exitosa, la sociedad ya contaba con los nuevos barcos cazadores Almirante Señoret y Almirante Goñi. Martinic, Historia ..., op . cit., 827.

26 Ibid., 826. 
estaba dotado de carbón, petróleo, municiones, toneles, herramientas diversas, un taller de reparaciones y equipos completos de escafandras; además de cargar las subsistencias. La tripulación del buque factoría estaba compuesta por el comandante, el primer y segundo teniente y dos jefes mecánicos, todos ellos parte del estado mayor del buque. El resto de la tripulación la componían los maestros trinchadores, los maestros mecánicos, un maestro encargado de la caldera, los marineros, los cocineros y camareros, entre otros. En total, se trataba de cuarenta a cincuenta hombres. Lo interesante del buque factoría es que una vez que llegaba a destino modificaba totalmente su identidad: de buque de transporte se transformaba en buque fábrica. Los catchers, cazadores o cañoneros, por el contrario, permanecían en su función, por un lado dependiendo del buque madre para su abastecimiento y, por el otro, alimentándolo constantemente de la materia prima proveniente de la cacería 27.

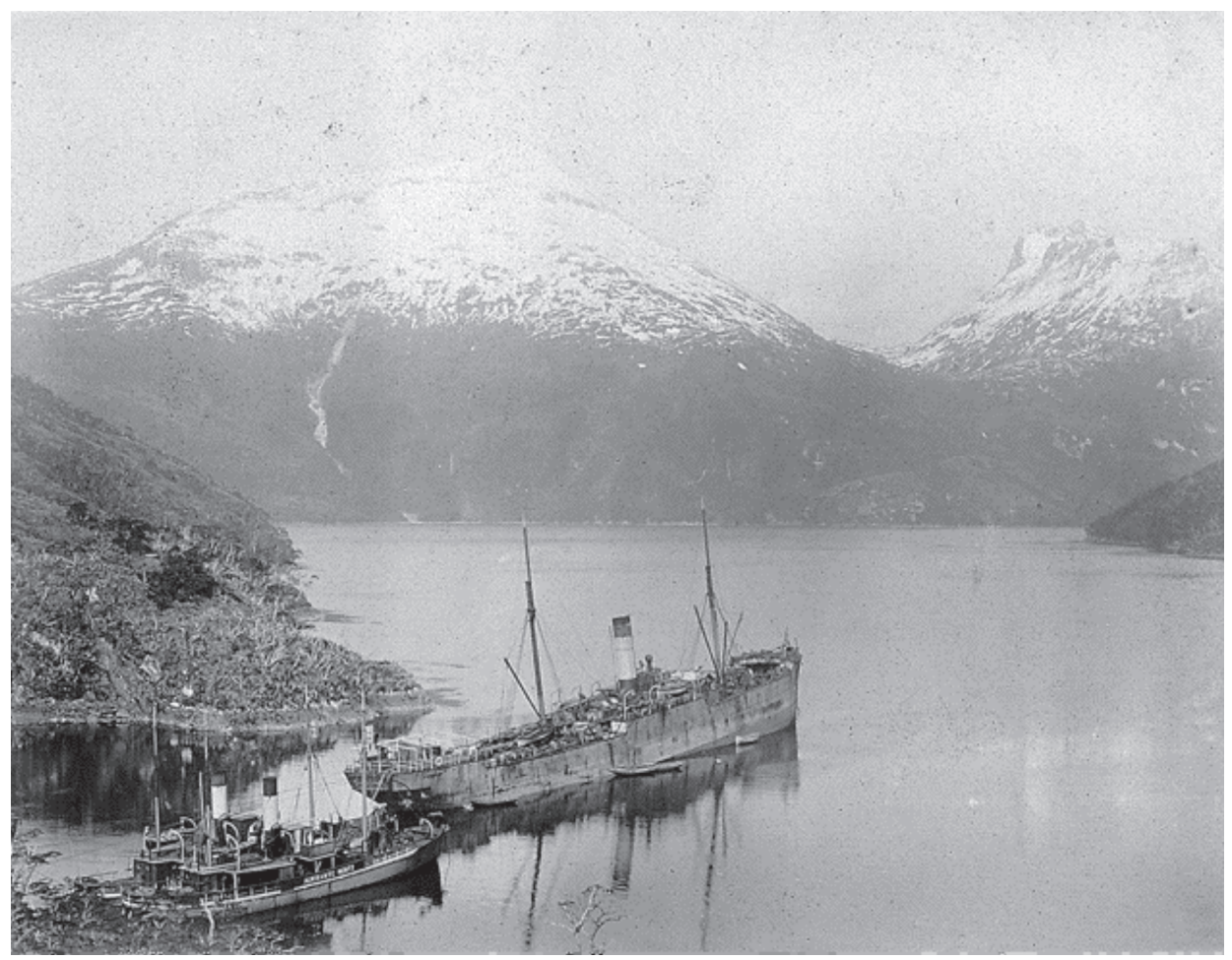

Navíos Gobernador Bories y Almirante Montt de la Sociedad Ballenera de Magallanes. Archivo Fotográfico, Instituto de la Patagonia, Universidad de Magallanes, Chile.

27 Jacques Liouville, Cétacés de L'Antarctique (Baleinoptères, Ziphiidés, Delphinidés), París, Masson et Cie. Éditeurs, 1913, 209-211. 
Sabemos que Andresen era el director o administrador de la compañía, pero ¿zarpaba junto a su tripulación en la campaña de caza propiamente tal? A juicio de Jacques Liouville, médico de la expedición de $\mathrm{Charcot}^{28}$, que tuvo la oportunidad de compartir algunos días con los balleneros antárticos a principios de siglo, cada compañía ballenera enviaba un director a los lugares de cacería, que desempeñaba además el rol de comandante; en el caso de la Compañía Ballenera de Magallanes, el director operaba en el barco usina Gobernador Bories. No obstante, quien comandaba dicho navío era el capitán de nacionalidad sueca Stolhane ${ }^{29}$. Sabemos además, que Andresen vivía en el Gobernador Bories, dotado de un hermoso y cómodo salón, como se verá más adelante, y presumiblemente sus labores como director-administrador de la empresa incluían numerosos viajes a Europa ${ }^{30}$, para hacerse cargo de las aristas comerciales de la compañía. Resulta entonces muy probable que Andresen no participara de manera permanente de las campañas de caza; sin embargo, ello no le impedía dedicarse de cuando en cuando a ellas. Liouville nos relató, basado en lo escrito en su diario de viaje a bordo del Pourquoi-Pas?, que en una oportunidad Andresen había zarpado a la cacería de la ballena en el Almirante Uribe, en tanto el capitán Hansen lo había hecho a bordo del Almirante Valenzuela ${ }^{31}$.

En el año 1909, la sociedad adquirió el pontón ${ }^{32}$ denominado Rubens que pertenecía a la Compañía de Vapores Lamport y Holt, para trasladarlo a Chiloé y habilitarlo como fábrica flotante de aceite ${ }^{33}$. El proyecto de la compañía consistía en abrir un centro de operaciones en la costa pacífica, ya que si bien la cacería se concentraba en las aguas antárticas, se practicaba también en el Pacífico hasta el archipiélago de Chiloé ${ }^{34}$. Nada se supo sobre dicho proyecto, pero todo indica que nunca pasó de ser una idea que no llegó a materializarse. En el año 1912, nos encontramos nuevamente con el pontón Rubens en Bahía Águila, pero sabemos que luego de haber sido chocado por el buque Gobernador Bories, arrastrado producto de una fuerte ráfaga de viento, se averió seriamente, penetrando gran cantidad de agua en él. Rápidamente el pontón fue trasladado por el personal de la compañía a la playa, con lo cual logró rescatarse la totalidad de la carga que almacenaba. La empresa evaluaba que este accidente no le había significado pérdidas, en primer lugar porque el Rubens estaba asegurado y en segundo porque la carga logró

28 Expedición realizada a la Antártica por el médico y explorador francés Jean Baptiste Charcot, entre los años 1908 y 1910.

29 Liouville, op. cit., 209 y 213.

30 Además de los viajes conocidos del capitán Andresen a Noruega, Charcot, en carta de octubre de 1911, dejó consignado que se había encontrado con el capitán noruego en Manchester, en el momento de su partida a bordo del Gobernador Bories con destino a Port-Lockroy. Ibid., 24.

31 Ibid., 219.

32 Benjamín Subercaseaux, al final de su libro Tierra de Océano, publicó un "Pequeño vocabulario marítimo de las voces que aparecen con más frecuencia en este libro". En aquellas páginas se puede leer: "Pontón: Barco desarmado y desmantelado, que se mantiene fondeado, y que sirve como depósito de carbón, de pertrechos, de lavandería, etc.”. Benjamín Subercaseaux, Tierra de Océano, Santiago, Ediciones Ercilla, 1946, 574.

33 Chile Austral, 2 de septiembre de 1909, 6

34 Véase Mateo Martinic, "Actividad lobera y ballenera en litorales y aguas de Magallanes y Antártica, 1868-1916”, en Revistas de Estudios del Pacífico 7, Valparaíso, 1973, 17. 
rescatarse, pero lo que es más importante saber es que: "Por otra parte el Rubens no era en absoluto necesario y si se le tenía en servicio era para ofrecer mayor comodidad. La mercadería que en el era depositada pasará a serlo en tierra donde hay galpones cómodos para el objeto" 35 .

La cita anterior confirma que el proyecto de convertir al Rubens en una fábrica flotante de aceite nunca se llevó a cabo o fue una empresa fracasada. La información disponible permite pensar que el Rubens siguió siendo utilizado hasta 1912 al menos como un pontón, es decir, como un buque utilizado para el almacenaje.

La tripulación de la flotilla la formaban en gran parte noruegos, con amplia experiencia en la actividad de cacería de cetáceos. Sabemos que, en 1903, Andresen había viajado hasta Ancud para contratar tripulación para la primera empresa que en esa fecha recién se estaba conformando, pero no disponemos de información que nos señale la nacionalidad de los hombres que la compusieron. Sí está claro que el viaje que Andresen, como socio de la Sociedad De Bruyne, Andresen y Cía., realizó a Noruega no solo era para adquirir un buque cazador y los implementos necesarios para la sociedad que se formaba, sino también para contratar "hombres con experiencia en la caza pelágica"36. La nacionalidad noruega de los marineros que componían la flotilla de la compañía se corrobora al leer algunos párrafos del artículo de un diario noruego reproducidos por el periódico puntarenense Chile Austral en septiembre de 1909. En dicho artículo, Julio Molzen realizaba una defensa de la sociedad, vilipendiada a su juicio por otros noruegos, que "aquí en su patria no encuentran por inhabilidad, el pedazo de pan que la Patagonia de Chile les brinda con largueza". Él, como antiguo empleado de la compañía, señalaba:

"Como esta sociedad ha merecido de otros noruegos expresiones en los diarios que no reflejan la verdad, me declaro con deber a manifestar desde estas acreditadas columnas, mis mas sinceros agradecimientos hacia el señor Jerente de la Sociedad, Capitan A. Andressen $[\ldots]$

Es este mi deber al hacerlo, pues mientras fui su empleado, me trataron con la mayor consideración, con la misma que tratan a todos sus subordinados, honrados y laboriosos" 37 .

Charcot también lo confirmó al hablar de la nacionalidad de los residentes de Bahía Águila y se vuelve a confirmar en la noticia publicada en la prensa de Punta Arenas del julio de 1910, que señalaba que el marinero noruego Eduardo Vincent, del vapor Almirante Montt, había sido encontrado muerto en Bahía Águila ${ }^{38}$.

Por su parte, Liouville, refiriéndose a las diferentes compañías que operaban en las zonas antárticas a principios del siglo XX, señalaba que estaban compuestas en su mayoría por noruegos. Excepcionalmente se embarcaban algunos suecos, dane-

Chile Austral, 21 de noviembre de 1912, 6.

Martinic, Historia..., op. cit., 826.

Chile Austral, 16 de septiembre de 1909, 6.

Idem, 20 de junio de 1910,6 . 
ses, estadounidenses y uno que otro marinero de otra nacionalidad, que subía a bordo en alguno de los puertos de escala de las largas travesías de las naves balleneras desde y hacia Europa. Si bien su comentario apuntaba sobre todo a las compañías noruegas que confiaban más en los marineros provenientes de su país de origen, por su experiencia marítima y ballenera basada en una larga tradición, este era extensivo a las de origen noruego-chileno o chileno, como es el caso de la Sociedad Ballenera de Magallanes ${ }^{39}$.

En el año 1910, la sociedad adquirió el vapor Telefon que pertenecía a la compañía Lloyds, pero que tras un accidente había sido puesto en remate. El accidente había ocurrido en la bahía del Almirantazgo de la isla Saint George -la mayor de las Shetland del Sur- y tuvo lugar cuando la flotilla llevaba un cargamento de barriles y carbón a una compañía noruega que realizaba la cacería de ballenas en los mares australes. Muy pronto se conoció la noticia en la isla Decepción y, de acuerdo a Charcot, se había producido una verdadera carrera entre los navíos de las diferentes compañías apostadas en la isla por acudir al lugar del naufragio. Fue el buque Almirante Valenzuela el que, pese a haber salido con retraso, logró adelantarse, de tal modo que fue Andresen quien saltó a bordo del Telefon e izó su bandera en él.

De acuerdo a la prensa de la época, la tripulación del navío debió ser rescatada por diversos barcos, tanto noruegos como los pertenecientes a la Sociedad Ballenera de Magallanes. Charcot proporcionó más información; según lo apuntado en su diario, al haber sido el Telefon completamente abandonado por su tripulación, quien lo abordara podía tomar posesión de él, que fue justamente lo que Andresen realizó. Inmediatamente el capitán noruego remolcó el Telefon hasta la isla Decepción. La intención de Andresen era reparar el barco de tal manera de conducirlo hasta Punta Arenas; sin embargo ello no fue posible, "por la falta de bomba, buzo y otros elementos" ${ }^{40}$. De ese modo, el barco seriamente averiado hubo de varar en la isla Decepción hasta noviembre, cuando los planes que Andresen tenía reservados para él comenzaron a desplegarse. Aquel mes, un capitán al mando del Gobernador Bories con seis tripulantes llegó al lugar donde el Telefon se encontraba encallado. A bordo llevaba una caldera, una bomba y diversas herramientas para que un buzo pudiera realizar la labor de rescate. Sin embargo, el hielo era muy espeso, de modo que:

"Andresen, con algunas tablas, hace construir trineos, y doce hombres marchan a buscar al Telefon. Está completamente cogido en el hielo; pañoles, caldera y máquina no forman más que un bloque compacto. Los noruegos que son los mejores marinos del mundo, no se desaniman por tan poco, y después de un trabajo encarnizado hacen uso de la caldera pequeña para fundir el hielo, vacían lo necesario del navío y -itras qué esfuerzos!- consiguen ponerlo a flote. El buzo comienza sus trabajos sin guantes, porque el desgraciado no esperaba encontrar el agua tan fría; se sumerge en el agua a $-0,8^{\circ}$ y por algunos minutos de trabajo en estas condiciones sufre después durante horas. Pero

39 Liouville, op. cit., 214-215.

40 El Comercio, Punta Arenas, 15 de marzo de 1909, 3. 
sin embargo, persiste; el Telefon es puesto a flote, y aprovechando un relajamiento momentáneo del hielo es vuelto a llevar a la ensenada de los Balleneros. Los desgarrones del casco son enormes, pero Andresen está persuadido de que llegará a taparlos con el cemento [...] 'Es una hermosa ballena me dice sonriendo""41.

Pese a los daños ocasionados por el accidente, Andresen confiaba en repararlo momentáneamente con cemento, de tal modo de hacerlo llegar por sus propios medios a la ciudad de Punta Arenas y de ahí a Europa, donde las reparaciones finales, mucho más baratas que en Sudamérica, lo devolverían a la vida de tal modo de integrarse a la flotilla. Estos fueron los planes del capitán Andresen; no tenemos la confirmación de si fue esta exactamente la forma en que el Telefon fue reparado ni si el itinerario trazado se siguió, pero un año más tarde Charcot, de regreso en Punta Arenas, comentaba en su diario:

“[...] hemos visto al Telefon que llegaba tranquilamente de Decepción con velocidad de diez nudos; sus banderas baten el viento; limpio y repintado, con Andressen ${ }^{42}$ y hasta la señora Andressen a bordo, la cual ha querido hacer la travesía con su marido. Es la mejor operación de reparación que se pueda imaginar"43.

El remate del Telefon se realizó luego de haberse formado un sindicato con quince socios, que lo ofrecieron al mejor postor, siendo adjudicado a la Sociedad Ballenera de Magallanes ${ }^{44}$. Por su parte, en el año 1911, el Gobernador Bories fue enviado a Europa para someterse a importantes reparaciones, que le permitieran efectuar sus labores de manera mucho más eficiente. Sin embargo, estas no fueron suficientes, a juzgar por la decisión de deshacerse de él años más tarde. En efecto, en 1914 la sociedad optó por venderlo en Inglaterra y reemplazarlo por otro de mayor tonelaje, lo que se llevó a cabo en junio de dicho año, con la adquisición del Senator, un vapor construido en 1983, que tenía 4.689 toneladas de capacidad y 3.049 de registro. El navío estaba dotado de luz eléctrica, construido en acero, contaba con dos cubiertas y sus dimensiones eran las siguientes: eslora, 400 pies 5 pulgadas; manga, 45 pies 3 pulgadas; y puntal, 29 pies 8 pulgadas. El barco debía ser acondicionado para la nueva actividad a la cual se lo destinaría, básicamente, la instalación de digestores para la preparación del aceite y tanques para su almacenamiento, con capacidad de hasta cuatro mil toneladas. Su objetivo sería actuar como una verdadera "fábrica flotante" 45 . El Senator llegó a tierras chilenas en marzo de 1915 y cambió su nombre a Gobernador Bories, haciéndole honor al buque que reemplazaba. Su tripulación contaba con 44 individuos y su comandante era el capitán E. Olsen.

41 Jean Charcot, El Pourquoi-Pas? en el Antártico. Diario de la expedición al Polo Sur en 19081910, Madrid, Calpe, 1921, 356.

42 En las primeras páginas de su diario en las cuales nombra al capitán noruego, Charcot escribe "Andresen", pero en páginas siguientes escribe "Andressen".

43 Charcot, op. cit., 357.

44 El Comercio, 24 de mayo de 1910, año XI, n ${ }^{\circ} 2935,3$.

45 La Unión, Punta Arenas, 14 de junio de 1914, 6. 


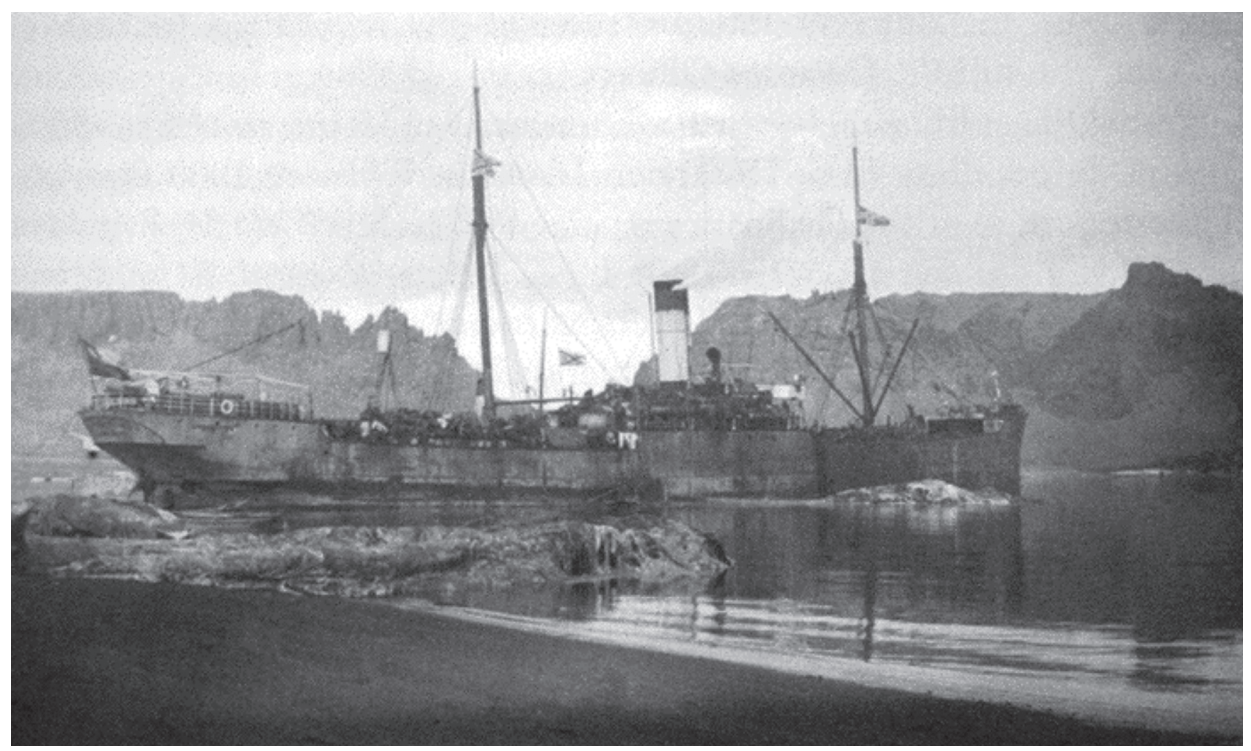

Navío Gobernador Bories perteneciente a la Sociedad Ballenera de Magallanes. Archivo Fotográfico, Instituto de la Patagonia, Universidad de Magallanes, Chile.

\section{El modus operandi}

Bahía Águila, como se ha señalado antes, fue la primera planta destinada al almacenamiento y tratamiento del aceite de ballena, establecida por la compañía en la península de Brunswick el año $1905^{46}$, donde funcionó hasta 1916, año en que la empresa remató la totalidad de sus instalaciones, luego de su liquidación. No obstante lo anterior, solo en septiembre de 1912, el ingeniero Hugo Pietrogandi viajaba a Bahía Águila para medir en terreno la concesión que el Estado le hacía a la sociedad para sus instalaciones balleneras. Hay que decir, sin embargo, que a juzgar por información posterior a dicho año, la concesión habría sido letra muerta ${ }^{47}$. En efecto, el año 1913, el gerente de la sociedad solicitaba a la Administración de Aduanas su "habitación", "con el objeto de que el vapor ballenero Gobernador Bories pueda proveerse de dicha caleta de los elementos y útiles necesarios para la expedición a los mares australes", solicitud que esta vez fue concedida ${ }^{48}$. De modo que es presumible pensar que Bahía Águila, pese a la burocracia involucrada en la solicitud de ocupación legal, funcionó desde el inicio de la sociedad y hasta 1916.

46 Betancourt, op. cit., 178-179; Lautaro Navarro señala que, en el año 1904, la sociedad en comandita formada por Andresen y de Bruyne había solicitado al gobierno el permiso correspondiente para la ocupación de Bahía Águila y a la vez había encargado la maquinaria necesaria para la instalación en dicho lugar de la planta de beneficio de ballenas, maquinaria que había llegado en mayo de 1905. Lautaro Navarro, Censo jeneral de población, edificación, industria, ganadería i minería del territorio de Magallanes, República de Chile, Punta Arenas, Imprenta de El Magallanes, 1907, 298b.

47 Chile Austral, 22 de septiembre de 1912, 6.

48 La Unión, 19 de noviembre de 1913, 6. 
La planta había sido habilitada desde un comienzo con todas las instalaciones necesarias para realizar el proceso a que era sometida la carne de ballena con la finalidad de obtener aceite, y sin lugar a dudas continuó en funcionamiento, pese a los dos incendios que sufrió en el tiempo. En el año 1916, cuando la sociedad decidió liquidarla, puso a remate público todas sus instalaciones. Observamos cuán bien equipada estaba. En ella funcionaba, en primer lugar, la casa de administración que contemplaba, además del edificio central, varios departamentos y jardines. Un segundo lote de infraestructura que se puso a remate en la ocasión estaba compuesto por el varadero, la maestranza y anexos. La maestranza contaba con un caldero, bomba de alimentación y chimenea, además de una serie de herramientas específicas para la faena. Había también en este conjunto un almacén naval, constituido por varios departamentos para depósito de mercadería y un taller de herrería. El lote $\mathrm{C}$ que se remataba, estaba constituido por las casas para los trabajadores, un galpón para las embarcaciones y un muelle antiguo. Otro lote estaba formado por un antiguo varadero para ballenas, así como un muelle en desuso. El lote E lo conformaba un terreno boscoso con dos frentes a la playa. Una serie de otros utensilios, maquinaria e infraestructura en general completaban la planta de Bahía Águila. La base además contaba con una línea telefónica, que se extendía desde la casa de administración hasta el faro San Isidro, con aparato de larga distancia ${ }^{49}$.

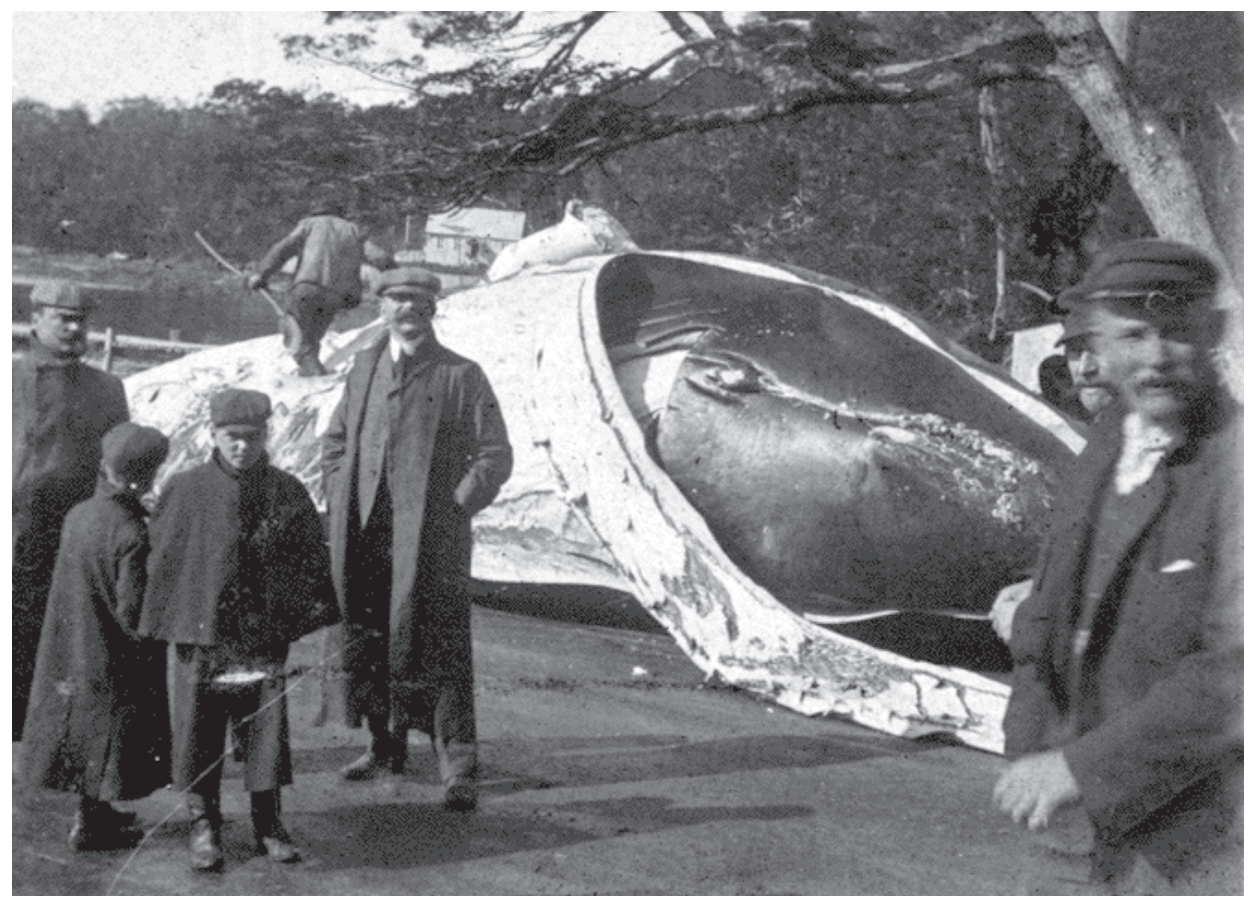

Bahía Águila, Península de Brunswick. Archivo Fotográfico, Instituto de la Patagonia, Universidad de Magallanes, Chile.

49 Idem, 14 de noviembre de 1916, 3 . 
Pero no solo esta planta actuaba como centro de operaciones de la compañía. En aguas antárticas de las islas Shetlands y vecindad, la Sociedad Ballenera de Magallanes estableció un punto neurálgico de las actividades balleneras. Fue la isla Decepción, con su particular geografía ${ }^{50}$, ya ocupada por otras empresas balleneras internacionales, la elegida para tal efecto. Armando Braun Menéndez ha explicado que Bahía Águila habría sido destruida tras el incendio que sufrió y, bajo esas circunstancias, Andresen y sus hombres se habrían trasladado a isla Decepción, para la temporada que se extiende desde noviembre de 1906 hasta abril de 190751 . Isla Decepción, parte de las Shetland del Sur, al estar en el corazón del territorio de cacería, aparecía como un lugar mucho más apto y sensato que un emplazamiento en la península de Brunswick, dado que el traslado con anterioridad de los cetáceos a Bahía Águila encarecía los costos de explotación del recurso ${ }^{52}$. No obstante, es altamente probable que luego de la instalación de la nueva base en la isla Decepción, la empresa haya reparado los daños ocasionados por el incendio en Bahía Águila, dado que esta siguió en funcionamiento hasta el cierre definitivo de la compañía en 1916, de modo de operar con ambas. En dicha isla tuvieron su base de operaciones tres compañías extranjeras, además de la Sociedad Ballenera de Magallanes. No obstante, los 220 habitantes de la base-estación en la isla eran en su gran mayoría de origen noruego, salvo las excepciones mencionadas antes, a los que se sumaban algunos chilenos que actuaban como maquinistas.

El modus operandi de la compañía era el siguiente: sus vapores se abastecían en Europa, preferentemente en Inglaterra, de carbón, barriles y otros materiales o insumos. En algunas ocasiones se realizaban acondicionamientos o reparaciones que les permitían afrontar de mejor manera la cacería de la ballena; tal fue el caso del vapor Telefon, rescatado por la flotilla de la sociedad magallánica y posteriormente adquirido por esta en remate, que emprendió viaje a Europa para ser restaurado en los astilleros del Viejo Continente ${ }^{53}$. Luego realizaban el viaje hasta el

50 Isla Decepción resultaba muy propicia para las actividades de las sociedades balleneras, ya que su particular forma actuaba como un espacio protegido en medio de las inclemencias del clima. Cordobez Madariaga la describió de la siguiente manera: "La Isla Decepción, por ejemplo, es un cono volcánico sumergido que ofrece no solo espléndidos fondeaderos a naves de todos los calados, es una bahía amplia y bien protegida, con buenas caletas...". Enrique Cordobez Madariaga, La Antártida Sudamericana, Santiago, Editorial Nascimento, 1945, 57.

51 El autor se refiere al primer incendio que afectó a Bahía Águila en febrero de 1908; no obstante isla Decepción efectivamente comenzó a ser ocupada como centro de operaciones de la sociedad en noviembre de 1906, por lo que es razonable afirmar que no fue el incendio el motivo de la ocupación de la isla sino las variables estratégicas. Armando Braun Menéndez, Pequeña Historia Antártica, Buenos Aires, Francisco de Aguirre, 1974, 124. Véase también Martinic, "Actividad lobera...", op. cit., 17.

52 Braun Menéndez, op. cit., 124.

53 Chile Austral, 12 de diciembre de 1910, 6. Cabe decir sin embargo, que algunas reparaciones también se realizaban en territorio nacional, como es el caso de la escampavía Âguila -que no era propiedad de la Sociedad Ballenera de Magallanes- y que en noviembre de 1909 ingresó al varadero de los señores Bonacich y C., con el objeto de ser sometida a reparaciones. Chile Austral, 3 de noviembre de 1909,6. La empresa aludida no es otra que 'Carlos Bonacich y Compañía', formada por los hermanos Daniel y Carlos, oriundos de la isla de Brac, hoy Croacia, asentados en Punta Arenas y con experiencia en el rubro de la reparación y construcción naval. Toledo, op. cit., 28-29. Martinic plantea que los intereses del grupo económico Braun Hamburger incluían el ramo de las construccio- 
puerto de Punta Arenas, desde donde se trasladaban a Bahía Águila, operando en las cercanías o bien navegando hasta la base de la isla Decepción, cuando se iniciaba la temporada en aquellas zonas de la Antártica. El viaje desde Europa hasta la isla Decepción tomaba 50 días, siendo cinco los puertos donde los navíos hacían escala para abastecerse de agua y carbón: Portland, en Inglaterra, San Vicente, en las islas del Cabo Verde, Bahía, en Brasil, Montevideo y finalmente las Islas Falkland o Malvinas ${ }^{54}$. La isla Decepción marcaba el final de la travesía y el punto de partida de su recorrido por "los mares del Sur", ya en plena labor de cacería.

Debe hacerse notar que Andresen, compenetrado de la actividad ballenera como estaba, había adquirido todos los conocimientos referentes a los últimos adelantos técnicos en materia de cacería de ballenas. En 1903, el capitán noruego había viajado a su país natal dispuesto a conocer el manejo del cañón arponero, inventado hacía poco por Svend Foyn. No solo se impuso de su funcionamiento, sino que además adquirió uno que llevó hasta las zonas antárticas, una vez de regreso en Chile ${ }^{55}$. Este cañón arponero fue aplicado para la cacería, como lo confirmó Braun:

\begin{abstract}
"A proa [los buques balleneros] llevan un cañón arponero colocado sobre una plataforma circular elevada, que permite su giro hacia el blanco. El arpón se coloca por la proa del cañón y el cartucho que ha de expelerlo como un disparo común por la parte posterior. Aquel arpón, largo de casi dos metros, tiene una punta aguda y cónica y lleva una granada explosiva seguida de una especie de anzuelo de cuatro garfios y está unido al cazador por un largo cable resistente que pasa por el cabestrante del buque y se envuelve a un costado. Cuando el barco se ha aproximado a la presa incauta unos veinte o treinta metros y cuando para respirar aparece en la superficie, el artillero apunta y dispara y si tiene buena puntería el arpón penetra en el cuerpo de la ballena un par de metros, estalla la granada en su interior y se abren los garfios, con lo cual queda sujeta. Es en balde que se sumerja en busca de refugio, se le da entonces soga y al cabo de un rato emerge en medio de aleteos y convulsiones hasta morir con la panza arriba" ${ }^{56}$.
\end{abstract}

La ballena cazada y muerta era inflada a través de un tubo que lanzaba aire en sus intestinos, de tal modo que hinchada no se hundía. En una campaña de caza en las cercanías del estrecho de Magallanes o costas del Pacífico y del Atlántico podían cazarse cuatro o cinco ballenas, que eran dejadas en estas condiciones y luego, en el viaje de regreso a la planta factoría de Bahía Águila, eran recogidas.

nes y reparaciones navales, aludiendo a la sociedad formada por la casa Braun \& Blanchard con los hermanos Bonacich (dueños del varadero y astillero más importante de Punta Arenas), que daría lugar a la formación de Bonacich Hermanos y Compañía en el año 1898. Martinic, Historia..., op. cit., 909 y Martinic, Ménendez y Braun..., op. cit., 203. Sin embargo, a pesar de ello, los navíos de la sociedad eran enviados a repararse al viejo continente. Por otra parte, en el año 1910, señalaba un editorial del periódico Chile Austral, que hacía tres años que se venían construyendo embarcaciones en el país con maderas nacionales, de una envergadura de 4, 8 y 10 toneladas, comentando que sus resultados habían sido "nada desfavorables". Chile Austral, 18 de septiembre de 1910, 8.

54 Liouville, op. cit., 210.

55 Martinic, Historia..., op. cit., 825

56 Braun, Memorias..., op. cit., 209. 
Por lo general esta operación tomaba entre diez y quince días, pero una campaña exitosa podía hacerse en solo tres ${ }^{57}$.

Cuando la campaña de caza se hacía en aguas antárticas, las naves de la compañía zarpaban juntas al estilo de una flotilla que iba a probar suerte en su empresa comercial, dando inicio de esa forma a la temporada alta de cacería en el mes de diciembre ${ }^{58}$. Eran los meses de diciembre (desde la Navidad) y enero los más productivos, tanto por el número de cetáceos capturados, como por la menor dificultad envuelta en la captura. Debe recordarse que en aquellos parajes, durante los meses de oscuridad total y los crepusculares, no se podía efectuar navegación alguna dada la ausencia de faros y balizas, en una zona caracterizada por la existencia de icebergs y arrecifes ${ }^{59}$. No obstante, en marzo la cacería continuaba, como lo informó el periódico Chile Austral de Punta Arenas, señalando que en marzo de 1909 los vapores balleneros Uribe, Montt, Valenzuela y Gobernador Bories se encontraban en la isla Saint George, Shetland del Sur ${ }^{60}$.

Cuando se hablaba de los "mares del sur", se hacía referencia a las islas Shetland ${ }^{61}$ y si bien el número de ballenas cazadas era variable, en una expedición podía llegarse a la centena, como ocurrió en marzo de 1909, cuando el vapor ballenero Almirante Valenzuela volvió desde aquellas islas, con 104 ballenas capturadas "de gran tamaño"62, o bien a triplicar dicha cantidad, como sucedió en 1915, período de bonanza al parecer, en que se capturaron 309 ballenas, lo que representaba un total de 2.068 toneladas de aceite y 14 de barbas ${ }^{63}$.

En los meses de otoño, invierno y primavera, la sociedad operaba en el estrecho de Magallanes y cercano tanto a las costas del Atlántico como del Pacífico, siendo en este caso, el centro de las faenas la factoría de Bahía Águila. Es frecuente entonces, encontrarse con este tipo de información en la prensa local de la época: “Ayer pasó frente a nuestro puerto [Punta Arenas] el vapor ballenero 'Almirante Montt' conduciendo a remolque cinco ballenas para Bahía Águila" 64 o "Pasó con dirección a Bahía Águila, el vapor ballenero 'Almirante Valenzuela' remolcando 3 grandes ballenas" 65 .

H. A. Broome fue invitado en una oportunidad por el capitán del Almirante Montt, Gunner Ohlssen, a ser espectador e incluso participar activamente de la

57 H.A. Broome, The Log of a Rolling Stone, Edinburgh, The Riverside Press Limited, 1913, 298.

58 No obstante, esta fecha podía adelantarse en algunos días, como ocurrió en 1909, cuando la flotilla de la sociedad zarpó hacia los mares del sur e islas Shetland a fines de noviembre. Chile Austral, 18 de marzo de 1909, 6.

59 Liouville, op. cit., 208-209.

60 Chile Austral, 14 de marzo de 1909, 6

61 En diciembre de 1906 el gobernador de Magallanes "autorizó a la Sociedad para instalar una estación de pesca y recalado en las Islas Shetland del Sur. La Sociedad estableció su principal base ballenera en la Isla Decepción y la mantuvo hasta 1914, dejando luego un depósito de carbón, fecha a partir de la cual los balleneros tuvieron que interrumpir su trabajo en ese lugar a causa del estallido de la Primera Guerra Mundial”. Mauricio Jara, "El territorio antártico chileno y la ley n 11.846 : ¿cuestión de política interna o externa?”, en Derroteros de la Mar del Sur 13, Lima, 2005, 64.

62 Chile Austral, 14 de marzo de 1909, 6.

63 Idem, 5 de marzo de $1915,6$.

64 Idem, 27 de junio $1909,6$.

65 Idem, 15 de junio 1909, 6. 
operación de caza. Broome comentaba que el barco permanecía extremadamente limpio, ya que una vez que la ballena era cazada, no se faenaba en él, sino que sencillamente se trasladaba a la planta de Bahía Águila. Muy importante para el capitán -continúa Broome- era acertar los tiros, ya que de no hacerlo podía correr el riesgo de perder el arpón y la cuerda, y todavía peor, perdía un bono equivalente a 1 libra esterlina, que se le otorgaba por cada ballena capturada ${ }^{66}$.

En la temporada de buen tiempo, cuando la cacería se concentraba en las Shetland, la isla Decepción era la base de operaciones de la flotilla, cuya tripulación en aquellos meses vivía ahí. No obstante, el procesamiento de las ballenas se hacía a bordo del buque factoría. Liouville, se refiere a su impresión de la isla Decepción:

\footnotetext{
"No hay la menor huella de construcciones sobre la orilla. Ni clips para izar las ballenas con un cabrestante hasta el lugar en que se hayan las calderas; ni planta terrestre con sus negras chimeneas; ni talleres; ni galpones para los toneles. Nada del clásico paisaje industrial de las balleneras visitadas en Noruega [...] Entonces ¿dónde obtiene esta gente su aceite?

Simplemente a bordo de los grandes barcos. Allí se encuentran las calderas, las palanganas, los talleres y la carpintería para reparar las barricas. Un montón de toneles vacíos ocupa en efecto su puente, cuyo pico no se ve, bajo cuatro filas de barriles [...]

Sus chimeneas echan humo permanentemente. Es una usina flotante [...]

[...] al menos cada dos horas, se redoblan los gritos de las aves, porque algo ha venido a turbar su reposo: es uno de los pequeños cazadores que franquea el paso, y trae hasta junto a los transportes, una, dos o tres ballenas, productos de su caza.

El animal es desatado; su cadáver va a aumentar el cuadro de despojos que flotan junto al gran vapor, y en los cuales trabajan hombres sumidos hasta los hombros, en delantales impermeables, armados de grandes cuchillos y desde embarcaciones planas.

Una vez que [el vapor] ha dejado el cuerpo del cetáceo, el cadáver atraca junto al 'cargo'. Algunos hombres suben a bordo y vuelven con paquetes. Se reembarcan rápido y el pequeño navío, luego de hacer sonar su sirena como despedida, navega por el paso y desaparece hacia alta mar, a caza de un nuevo botín"67.
}

Liouville nos informaba que por lo común la faena destinada a la obtención del aceite de ballena implicaba unas 48 horas de trabajo para un equipo compuesto por 20 a 30 hombres. El procesamiento del producto incluía el corte y cocimiento del tocino y el posterior almacenaje del aceite obtenido en barriles. Sin embargo, en las regiones antárticas, las compañías balleneras trabajaban día y noche, de modo que un gran balenóptero podía estar "finalizado" en 24 horas ${ }^{68}$.

A comienzos del siglo XX, el principal producto de la ballena destinado al comercio era su aceite. José Betancourt, reproduciendo las observaciones que Liouville realizó de la actividad ballenera antártica, describía el procedimiento por el cual se obtenía el cotizado líquido: se utilizaba solo el "tocino", que en lenguaje técnico significaba la carne de la ballena, el cual se obtenía a través de cortes de

\footnotetext{
66 Broome, op. cit., 296.

67 Liouville, citado por Betancourt, Una industria en..., op. cit., 183-184.

68 Liouville, op. cit., 228.
} 
unos 50 centímetros de ancho en algunos casos, en tanto en otros, las franjas eran de mayor calibre. Esta ardua labor tomaba largo tiempo, porque se hacía mientras la ballena estaba amarrada junto al barco cazador. Esta es una característica interesante de la caza pelágica de principios de siglo: la mayor parte del proceso de elaboración del producto no se realizaba en tierra, sino en los barcos-usinas. El cadáver de la ballena amarrada era abordado desde embarcaciones planas que se situaban junto a él y por otros operarios que trabajaban sobre el cuerpo del cetáceo. Luego, existía un segundo equipo de operarios que reducía los cortes de "tocino" a rectángulos de 10 por 20 centímetros, los que finalmente eran echados a las calderas que proporcionaban el preciado aceite ${ }^{69}$.

No obstante, la primera memoria que la Sociedad Ballenera de Magallanes presentaba en diciembre de 1906 señalaba que si bien se habían enviado a Europa 40 toneladas de aceite, "quedaban en establecimiento" 109 toneladas más del preciado líquido, 10 toneladas de barbas y aproximadamente 100 toneladas de hue$\operatorname{sos}^{70}$. Por su parte, Mauricio Braun señalaba en sus memorias que la ballena cazada era remolcada prontamente a sus bases o bien al buque-factoría, donde luego de ser dejada en la cubierta, comenzaba de inmediato a ser procesada. Lo primero que se extraía era la grasa, con el objeto de derretirla en las calderas y obtener el aceite. Luego, en el caso de haber frigorífico, se extraían pedazos de carne del lomo que servían como un buen alimento en caso de apuro ${ }^{71}$. Las barbas se apartaban en seguida y su destino, de acuerdo al autor, era la fabricación de corsés, peinetas, cepillos, entre otros productos de uso doméstico. En algunas ocasiones se almacenaba la sangre, ya que seca constituía un buen abono, y finalmente la osamenta de la ballena era triturada, ya que servía como alimento para aves y como fertilizante ${ }^{72}$.

Pese a que Braun habla de varios destinos de los productos de la ballena, lo cierto es que fue el aceite indiscutidamente el principal. La carne a la que hace referencia el empresario es casi un dato anecdótico, en tanto servía solo para consumo de la tripulación "en caso de apuro". No obstante, hubo algún intento al menos de ensanchar la base de producción de la cacería ballenera en general, como lo demuestra el prospecto de la Sociedad Ballenera y Pescadora de Valdivia del año 1907, en el cual se manifestaba la intención de extraer el aceite no solo de la carne de la ballena, sino también de los huesos; utilizar la carne fresca como alimento para animales vacunos y caballares, y la carne que ya tenía cuatro o cinco días, es decir no fresca, junto a los intestinos del animal, utilizarlos como guano;

69 Betancourt, op. cit., 182.

70 Navarro, op. cit., 298c

71 Liouville tuvo la oportunidad de probar la carne de diversos balenópteros a bordo del Pourquoi-Pas?, y relataba que la experiencia, lejos de haber sido considerada como una prueba, le dejó un recuerdo muy agradable. A diferencia de las carnes de foca y de pájaro bobo, que la tripulación debió consumir como recurso alimenticio en los meses de invierno, la de la ballena le recordó el sabor del ternero de primera calidad. Liouville, op. cit., 109.

72 Braun, Memorias..., op. cit., 210. No se ha podido encontrar otra fuente que corrobore lo que señaló Braun, en el sentido de que no solo se utilizaba el tocino de la ballena sino también los huesos, la sangre, etc., lo que habría permitido matizar el argumento de la subutilización de la ballena cazada, desarrollado más adelante en este artículo. 
finalmente, los huesos a los cuales se les había extraído el aceite, servirían molidos como un abono artificial. Al abrir el abanico de explotación comercial de la ballena, se estimaba que el valor productivo de esta aumentaría en un $50 \%$ de lo que hasta ese momento se obtenía, al utilizar solo el tocino para la obtención de acei$\mathrm{te}^{73}$. No sabemos si el prospecto de la sociedad valdiviana tuvo éxito, pero sí está claro que no fue hasta la segunda mitad del siglo XX que comenzó a explotarse y comercializarse la carne de ballena, aunque fuera en pequeña escala, siendo además discutida su importancia como recurso alimenticio para la población chilena, cuya ingesta proteica resultaba deficiente ${ }^{74}$.

Por su parte, la prensa regional de la época hablaba de aceites y barbas como los dos productos faenados de la ballena, que eran trasladados para su comercialización a Europa por los propios barcos balleneros de la compañía o en algunos casos por barcos ajenos a ella, presumiblemente para destinar la totalidad de la flota de la empresa a la actividad de caza en épocas de abundancia:

"Llegó el vapor ballenero Almirante Uribe, procedente de la Bahía Águila, y conduciendo un importante cargamento de barba de ballena con destino a Europa. Esta carga la trasbordó hoy mismo al vapor Frances 'Villa de París', a llegado [sic] anoche de Valparaíso. El Uribe hará agua y carbón y en seguida zarpará nuevamente a Bahía Águila"75.

En el año 1911 ocurría algo similar: el capitán del barco noruego Unión, que había arribado a puerto en la ciudad de Punta Arenas trayendo un cargamento de maderas y mercadería para los señores Stubenrauch y Cía., planeaba volver a la brevedad a Europa, esta vez cargado con 500 toneladas de aceite de ballenas de la Sociedad Ballenera de Magallanes ${ }^{76}$. La sociedad operaba, entonces, contratando los servicios de barcos de otras compañías, que probablemente debían hacer el viaje a Europa por otras razones, o bien utilizando su propio buque-factoría, el Gobernador Bories. Era este, el buque-factoría, el destinado entre las naves de la compañía para hacer el viaje a Europa cargando el aceite y volver abastecido para las expediciones de cacería en las tierras antárticas. Se conoce de viajes hechos por este buque en los meses de abril, junio y octubre, es decir con anterioridad al inicio de la temporada de caza en las islas Shetland ${ }^{77}$.

La mayoría de los productos faenados de la ballena eran destinados a la exportación hacia Europa. Glasgow, en Inglaterra, centro del mercado de aceites de ballena, era lugar obligado en la travesía ${ }^{78}$. No obstante, sabemos que también se comercializó este aceite en el mercado nacional, donde era altamente demandado

73 Sociedad Ballenera y Pescadora Valdivia, op. cit., 1, 2 y 5.

74 Véase por ejemplo Alejandro Valle Pavez, Cecinas blandas de carne de ballena, Tesis presentada como parte de los requisitos para optar al título de Ingeniero Agrónomo, Universidad de Chile, Santiago, 1966.

75 Chile Austral, 11 de septiembre de 1909, 6.

76 Idem, 16 de abril de 1911, 6.

77 En estos meses, cuando la sociedad no operaba en las islas Shetland, los cazadores no dependían del buque-factoría, ya que su labor se reducía a la cacería y transporte de las ballenas a la planta de Bahía Águila.

78 Liouville, op. cit., 210. 
por las actividades mineras y por ferrocarriles, en este último caso como lubricante. Así por ejemplo, en el año 1907, Ferrocarriles del Estado solicitaba 28 mil libras de aceite de esperma ${ }^{79}$. De modo que no sorprende que en el año 1911 se informe en la prensa local de Punta Arenas que los señores Stubenrauch y Cía. habían enviado a Antofagasta, en el vapor Corcovado, 40 barriles de aceite de ballena con un peso neto de 8.399 kilos. Lamentablemente no se informa del destino final de dicho cargamento, pero es presumible que su destino haya sido consumo local ${ }^{80}$.

\section{Crisis, repunte, crisis terminal}

En el año 1909, la Sociedad Ballenera de Magallanes había experimentado una baja en sus utilidades. Dentro de las razones que explican los magros resultados económicos de aquel año, están las fluctuaciones que sufrían en el mercado internacional los precios de los productos comercializables derivados de la cacería de la ballena $^{81}$. En efecto, ese año los precios del aceite y barba de ballena, los dos productos exportables (con claro predominio del primero), habían decaído considerablemente. A ello se sumaban factores de riesgo, como podían ser un escaso número de ballenas capturadas o accidentes, como el que ocurrió en el año 1908, al producirse un incendio en la estación ballenera de Bahía Águila. En dicha ocasión, la empresa sufrió cuantiosas pérdidas, sobre todo porque ninguna de las instalaciones arrasadas por el fuego estaba asegurada -por no haber ninguna compañía que quisiera hacerlo-. Accidentes ocurrían sin lugar a dudas, por lo arriesgado del tipo de operaciones que implicaba la cacería de ballenas en los mares australes, o simplemente por las condiciones y características de la navegación a principios del siglo XX. Así, por ejemplo, el temporal que debió enfrentar el vapor Gobernador Bories rumbo a Europa y que lo obligó a arrojar una cantidad de barriles vacíos al mar, que tampoco estaban asegurados, fue considerado otro de los elementos que arrojaron un balance negativo de la empresa en el año 190982. La compañía, a raíz del incendio, se planteaba abrir una cuenta de seguros interna, la cual sería permanentemente actualizada, de modo de llegar a contar con una suma de dinero similar al costo de las instalaciones que poseía, para poder hacer frente a un eventual accidente de ese tipo ${ }^{83}$.

En septiembre del año 1909, la sociedad decidió finalizar sus actividades, al no haber suscrito la totalidad del capital autorizado. Bajo esas circunstancias levantó una petición al gobierno, para poder disminuir el capital pagado, que era de un $60 \%$, pero esta fue negada, forzando a la compañía a cerrar ${ }^{84}$. No obstante, se reorganizó inmediatamente sobre nuevas bases. Así, el 6 de junio de 1910, por escritura pública, se formaba la nueva sociedad con un capital de 60 mil libras

\footnotetext{
79 Martinic, “Actividad lobera...", op. cit., 16 y Betancourt, op. cit., 176.

80 Chile Austral, 26 de enero de 1911, 6.

81 Gastón Carreño, "La cacería de ballenas en las costas de Chile" [documento inédito], 4.

82 Chile Austral, 18 de marzo de 1909, 6.

83 Idem.

84 Martinic, “Actividad lobera...", op . cit., 20.
} 
esterlinas $^{85}$. Sin duda todo el aprendizaje acumulado en los años anteriores se aplicó en la reorganización de la sociedad. Como nos señala Martinic:

"Para aumentar sus ingresos la compañía intensificó las operaciones de invierno en aguas del Atlántico, logrando excelentes capturas de ballenas finas; además, las campañas de caza por aguas del Pacífico hasta Chiloé también resultaron productivas, permitiendo entonces un equilibrio del presupuesto social" ${ }^{\prime \prime}$.

El optimismo parecía campear entre los protagonistas de la reconstituida sociedad, ya que se hablaba por ejemplo de que las nuevas dependencias de la Sociedad Ballenera de Magallanes ${ }^{87}$, que se ubicarían en los altos de la casa de negocios de los señores Ladouch y Cía., "se están arreglando con grandes comodidades para el público y el confort para los empleados" 88 ; del mismo modo, al anunciar la reunión de accionistas de la nueva empresa para dar cuenta de su marcha así como de su memoria anual, se planteaba que "esta reunión se considera muy importante pues en ella se verá que la Sociedad Ballenera adquiere cada año mejores elementos y toma nuevos y grandes impulsos" 89 . Más aún, en la reunión de accionistas de enero de 1911, el gerente de la sociedad, Augusto Henkes, fue felicitado por los buenos resultados obtenidos por la empresa, que mostraba utilidades considerables ${ }^{90}$. Informaciones como la siguiente dan cuenta de que en la segunda década del siglo, luego de su reorganización, la compañía estaba dando dividendos:

“El vapor de la Sociedad Ballenera 'Gobernador Bories' saldrá próximamente para la costa del Pacífico a fin de continuar con sus faenas de pesca.

Este vapor trajo de los mares del sur 1800 toneladas de aceite de ballena, cuyo producido asegura el año financiero de la Sociedad nombrada" $"$.

En el año 1912 el capitán Andresen, de acuerdo a lo que nos relata Martinic, decidió retirarse de la sociedad, tanto por razones de salud como por diferencias de criterio sobre la organización de los negocios ${ }^{92}$; sin embargo, ello no pareció afectar la prosperidad de la sociedad, que aún vería años exitosos en cuanto al número de ballenas cazadas.

El período de bonanza económica de la empresa sin duda debe haber ocasionado algún tipo de beneficio para la ciudad de Punta Arenas, como fue lo que ocurrió en 1913, cuando en el marco de las obras de remodelación del muelle de pasajeros, el gerente de la sociedad, Henkes, obsequió dos lámparas eléctricas para iluminar la entrada de la gobernación marítima ${ }^{93}$.

85 El Comercio, 10 de junio 1910, 3.

86 Martinic, "Actividad lobera...", op . cit., 20.

87 La nueva sociedad conservó el nombre de la antigua que se disolvió: Sociedad Ballenera de Magallanes.

88 Chile Austral, 16 de agosto de 1910,8.

89 Idem, 10 de diciembre de 1910, 6.

90 Idem, 18 de enero de 1911,8 .

91 Idem, 21 de abril de 1912, 6.

92 Martinic, “Actividad lobera...", op . cit., 20.

93 Chile Austral, 11 de abril de 1913, 6. 
En el año 1913 nuevamente se incendiaban las instalaciones de la compañía en Bahía Águila; esta vez había seguros comprometidos, sin embargo, se estimaba que los perjuicios serían significativos, debido al atraso de las diversas actividades, producto de la destrucción de la planta ${ }^{94}$. Sea por este tipo de accidentes, sea por la baja del número de cetáceos capturados, o bien por los factores externos derivados de las fluctuaciones de los mercados internacionales, lo cierto es que luego de unos cinco años de reorganizada la sociedad, esta nuevamente mostraba pérdidas en su balance. Pese a ello, la visión era optimista; se calculaba que las pérdidas serían revertidas con las utilidades que otorgaría el vapor Gobernador Bories, comprado en fecha reciente. Pero el optimismo no dio sus frutos, porque en mayo de 1916, se hacía un llamado público a los accionistas de la compañía para que acudieran a cobrar 25 chelines por acción, dada la liquidación de la sociedad ${ }^{95}$. Meses antes, la sociedad estaba ya gestionando la venta de sus vapores destinados a cabotaje. Escuetamente se sabe que los vapores de la otrora próspera compañía, fueron vendidos a una firma japonesa ${ }^{96}$. A ello siguieron los llamados a los accionistas, esta vez para cobrar su segundo dividendo de diez chelines por acción, y luego la venta de la infraestructura de Bahía Águila: una caldera marina, dos digestores de presión, catorce estanques de varios tamaños. Finalmente un remate que tendría lugar justamente en Bahía Águila “[...] era el fin de la compañía97.

\section{SOBRE EL SIGNIFICADO DE LA EXPLOTACIÓN BALLENERA}

\section{El factor económico: el móvil para la arriesgada empresa ballenera}

Sin lugar a dudas, la motivación principal que llevó al establecimiento de la Sociedad Ballenera de Magallanes fue el potencial que, en términos económicos, una empresa de ese tipo podía ocasionar. Si consideramos el capital inicial con el cual la sociedad echó a andar su proyecto, esto es $£ 100.000$, y lo comparamos con las cifras que fueron publicadas en la Segunda Memoria y Balance del año 1910, vemos que la empresa había sido extremadamente exitosa en sus primeros años de funcionamiento. Este último señalaba que la sociedad poseía un capital de $£ 24.474,19,5$ en infraestructura, que incluía desde plantas de procesamiento hasta maquinaria diversa. La flota era avaluada en $£ 33.651,1,10$, sumando el gran total, donde se incluían otras "partidas", $£$ 83.802,10,7. La utilidad líquida, específicamente del año comprendido entre el 30 de septiembre de 1906 y el 30 de septiembre de 1907 , alcanzaba a la cifra de $£ 26.327,10,998$.

Los accionistas y directores de la compañía estaban satisfechos con los resultados, y como lo señalaba Braun en carta del 26 de abril de 1907 a Juan Blanchard:

\footnotetext{
94 Idem, 18 de enero de $1913,6$.

95 El Comercio, 15 de mayo de 1916, 2.

96 Idem, 30 de junio, 1916, 2.

97 Idem, 12 de octubre de 1916, 2 y 11 de noviembre de 1916, 3 .

98 Navarro, op. cit., 298c.
} 
"Ud. se extrañará que le diga que se ha cazado en poco menos de una semana 26 ballenas finas (Right Wales) cuyo valor se estima en más o menos $£ 15.000$. Esta es una caza maravillosa y no se conoce en la historia de que en un solo punto y en tan poco tiempo se haya atacado ese número de ballenas finas"99.

La cacería de ballenas en las zonas antárticas a principios del siglo XX era un buen negocio, y así lo debieron entender los socios capitalistas de la compañía, que insistieron en continuar con ella, pese a los inconvenientes de distinta índole que se fueron presentando a lo largo de los años. Incluso en su fase terminal, la sociedad confiaba en que la compra del nuevo Gobernador Bories, permitiría su repunte:

"Los accionistas de esta Sociedad se reunieron ayer para tomar conocimiento de la memoria y balance presentado por el Directorio.

Aunque el balance arroja saldo en contra, esta pérdida será cubierta con creces con el mayor valor que hoy tiene el vapor 'Gobernador Bories', comprado antes de la guerra; valor que asciende casi al doble de su precio de costo" 100 .

No obstante, el Gobernador Bories prácticamente no pudo cumplir las tareas para las cuales había sido adquirido. Siguiendo a Martinic, las dificultades ocasionadas por la Gran Guerra, así como las impuestas por las pretensiones británicas sobre las islas Shetland, habrían llevado a su disolución final ${ }^{101}$.

\section{En torno al concepto de sustentabilidad de la caza}

"Desde el mediodía a las dos y treinta de la madrugada navegamos en busca de ballenas por la parte de la isla Livingstone, luego por los alrededores de Salirock. Varias veces hemos advertido muchos cetáceos, persiguiéndolos; pero con tan mala suerte que, o bien se escapaban con facilidad, o bien no se ponían a tiro de cañón [...] A pesar del deseo que tenía de ver salir airosos a nuestros amigos, y de asistir yo mismo a las diferentes fases de la captura confieso que no me contrariaba mucho el que fuesen escapándose estos pacíficos y colosales animales, y con cierta alegría veía como se alejaba la pequeña mancha negra, destacándose en el mar en calma, azul, coronado por el estrepitoso chorro de vapor de agua.

Hemos sin embargo, perseguido una pareja de ballenas azules, navegando dichosas y confiadas, tras una serie de maniobras muy hábiles, una de ellas pasa al alcance de nuestro cañón; el capitán dispara con extraordinaria sangre fría. El animal es alcanzado [...] A lo lejos veo constantemente a su pobre compañera, ahora solitaria; no marcharán ya juntas, en una intimidad que acaso tuviese su dulzura, por las grandes extensiones glaucas, los valles y las grutas fantásticas de la arquitectura submarina de los icebergs, que habrían debido protegerlas contra la crueldad de los hombres"102.

99 Carta del 26 de abril de 1907. Archivo Mauricio Braun, Correspondencia Despachada, vol. 17, folio 948. Citado en Martinic, Historia..., op . cit., 826

100 El Comercio, 22 de enero de 1916, 2.

101 Martinic, Historia..., op. cit., 828 .

102 Charcot, op. cit., 369. 
Sorprende encontrarse con una descripción y juicio sobre la cacería de la ballena en la Antártica como esta, considerando que fue realizada contemporáneamente, es decir en la primera década del siglo XX. Su autor, Jean Charcot, parece haber quedado sensibilizado al presenciar la cacería de las ballenas, invitado por la Sociedad Ballenera de Magallanes en uno de sus viajes de rutina. Llama la atención sobre todo que el médico y explorador francés base su apreciación en la crueldad envuelta en el acto de caza y llegue incluso a utilizar un lenguaje metafórico, que personifica a los cetáceos, expresando sus sentimientos de pesar, frente al acto de muerte presenciado. En otro momento Charcot diría: "definitivamente yo no serviría para cazador" 103 .

El pasaje citado in extenso envuelve una crítica a una actividad que a comienzos del siglo XX era considerada ventajosa en varios frentes: a nivel económico, a nivel geopolítico y a nivel del desarrollo general de la región. Nada semejante a la defensa que ocasionó la cacería indiscriminada del lobo marino ocurrió con la caza de la ballena en las zonas australes. Probablemente por la abundancia de cetáceos que en ese período existía en la zona antártica.

La cacería del lobo marino se remontaba en la zona de Magallanes al siglo XVIII, siendo tan feroz que hacia fines de la centuria siguiente la población de dichos mamíferos había sido diezmada de una manera alarmante. La ausencia de regulación estatal en materia de explotación de recursos naturales, al igual que en un sinnúmero de otros aspectos, como lo revela la siguiente cita, había llevado a la semiextinción no solo de lobos marinos, sino también de focas y nutrias: "[...] recordar tambien debemos que perdemos millares de pesos en este territorio por falta de reglamentación de la corta de madera, de la explotación libre del otro, y del robo y destrucción pirática de las riquezas que nos brindan las loberías australes"104.

Avanzada la primera década del siglo XX, la cacería del lobo marino seguía practicándose, pese a que hacia fines del XIX ya se habían decretado dos vedas, una en 1892 y otra por cuatro años en $1893^{105}$. Con posterioridad al fin de la última veda aludida, la depredación tomó la forma de concesiones o arrendamientos de parte de las autoridades, no cesando por ello la caza inescrupulosa, que llevó a la disminución de la especie, a la vez que contribuyó a la formación de varias fortunas en la ciudad de Punta Arenas. Sin embargo, a esa fecha ya no constituía un negocio rentable como lo había sido en el pasado, debido a la presencia de especuladores que compraban las pieles a bajo costo y las revendían a precios mucho más convenientes en las curtiembres de Londres ${ }^{106}$. Uno de los aspectos que más llama la atención en la cacería del lobo marino es la tardía regulación en la materia, que había llevado incluso a la cacería de las hembras en el período en que amamantaban a sus crías, que indefensas y sin alimentación, también morían. La especie estaba amenazada y eso daba que hablar, como lo deja ver un editorial de un

\footnotetext{
103 Ibid., 370.

104 La Razón, Punta Arenas, 22 de febrero de 1895, 1.

105 Martinic, "Actividad lobera...", op . cit., 9-11.

106 El Comercio, 20 de diciembre de 1909, 3 y 4.
} 
periódico puntarenense, que se preguntaba qué habían hecho los poderes públicos para proteger la especie en peligro ante la "guerra a muerte" que habían iniciado comerciantes abusivos ${ }^{107}$.

Nada de ello ocurría con la cacería de la ballena. Al no haber legislación que regulase la cacería de los cetáceos en este período, y al existir en abundancia en la zona antártica diversas especies, estas se cazaban en grandes cantidades ${ }^{108}$, pero al realizar una parte importante de la faena en los barcos-usina sin las maquinarias propias de una planta terrestre, se desperdiciaba mucho potencial producto. De ese modo, solo se obtenía aceite de su carne. Francis Downes Ommanney se refirió de una manera lapidaria a la situación de explotación indiscriminada de la ballena en la zona antártica. Si bien, sus críticas apuntaban sobre todo al período posterior a la Primera Guerra Mundial, por los antecedentes con que contamos, son perfectamente aplicables a las primeras décadas del siglo XX:

"Las ballenas eran despedazadas en el agua al costado del barco y sus restos se abando-
naban a la deriva en el fondeadero, porque solo se aprovechaba la grasa en aquellos
días, los antiguos y malos días de la pesca de la ballena en el Antártico, por lo que los
desperdicios son enormes. Hoy día, después de transcurridos 40 años, cuando el fondea-
dero de la Isla Decepción se halla desierto y silencioso, sus negruscas arenas continúan
sembradas de huesos de ballenas, como un monumento a ese insensato sacrificio"109.

Según Liouville, las factorías flotantes de la Antártica solo producían aceites tipo 1 y 2 (una clasificación según contenidos de ácidos grasos libres) en tanto las factorías terrestres además de estos, producían aceites tipo 3 y 4 . Ello ya está hablando de que existía la posibilidad de utilizar de mejor manera el cuerpo de la ballena cazada. Continuaba Liouville, señalando que uno de los principales vicios de las compañías balleneras en la Antártica era el hecho que faenaran solo la superficie de los cetáceos, lo que según sus cálculos llegaba a un $60 \%$ del potencial de la ballena. Todo aquello que no era procesado para obtener el producto final -el aceite- era considerado "despojo", que por lo general se echaba al mar, o era parte del paisaje de las cubiertas de los buques balleneros. Así, las osamentas de la ballena, cargadas de aceite, eran abandonadas; lo mismo ocurría con los intestinos, las vísceras, la médula espinal, el cráneo y la lengua: "El hombre no aprovecha sino el 60 por ciento de esta oferta generosa producto de la abundancia de la vida marítima: pierde en consecuencia ¡cerca de la mitad!" 110.

Finalmente, el médico francés argumentaba que una serie de otros factores, tales como la abundancia de ballenas en la región, la competencia entre sociedades balleneras y lo costoso del procesamiento en el agua incidían en las caracte-

107 Idem.

108 Liouville nos informa que en las temporadas de abundancia de ballenas, las compañías preferían cazar la ballena azul, siendo la especie denominada "megáptera" la menos preciada, por su menor rendimiento comparativo en aceites y barbas. Liouville, op. cit., 219.

109 Francis Downes Ommanney, El océano, México, Breviarios del Fondo de Cultura Económica, $3^{\mathrm{a}}$ ed., 1966, 224-225.

110 Liouville, op. cit., 229. La traducción es nuestra. 
rísticas que adoptaba la explotación, de tal modo que para obtener dividendos económicos de la actividad ballenera hubiera que "matar y explotar el máximo de cetáceos en el mínimo de tiempo"111. Resulta interesante enfatizar este aspecto de la cacería -explotar el recurso al máximo, para competir con las otras sociedades balleneras existentes en la zona-, porque ello habla precisamente de la ausencia de regulación estatal en el plano de la explotación de recursos naturales, que de ese modo dejaba al arbitrio de las compañías los criterios de operación en la materia ${ }^{112}$. Y todo indica que el criterio de las compañías, incluida la Sociedad Ballenera de Magallanes, fue netamente comercial.

Charcot concordaba con la apreciación de su colega, señalando que la abundancia de ballenas, unida a la competencia que se generaba entre las distintas compañías que surcaban los mares australes, llevaba a los balleneros a solo faenar las partes más "remuneradoras" del cetáceo, desperdiciando el resto"113. Es bastante clara además su descripción de la bahía de isla Decepción: "Restos de ballenas flotan por todas partes, y cadáveres a punto de ser despedazados están tumbados junto a los diferentes barcos. El hedor es insoportable"114.

La Sociedad Ballenera y Pescadora Valdivia, por su parte, en su prospecto de “engrandecimiento del negocio" del año 1907, planteaba que hasta ese momento solo se utilizaba el tocino de la ballena para la obtención de aceite, "teniéndose que arrastrar a la mar con dificultades el enorme cadáver" 115 , lo que confirma que el mamífero marino era subexplotado.

La cacería de ballena, tal como la practicaban las empresas apostadas en la isla Decepción, utilizaba todos los adelantos técnicos que en la materia se habían desarrollado hasta ese momento: el cañón arponero, los buques más rápidos que permitían alcanzar a las especies de cetáceos más veloces y sobre todo la práctica de la caza pelágica, que indudablemente reportaba un número mucho más elevado de capturas que la caza costera. Era para la época una cacería moderna, pero poco sustentable. No había regulación alguna que normara por ejemplo el número de especies capturadas o el número de barcos cazadores que podían operar en una campaña ${ }^{116}$, y este silencio en regulación estatal era un silencio de la opinión pública también. Solo las voces de los exploradores, médicos y naturalistas extranjeros que llegaron a los remotos parajes de las cercanías de la Antártica vieron más allá de la rentabilidad económica de la explotación ballenera y a su modo criticaron la debilidad existente en materia de sustentabilidad.

111 Idem.

112 Liouville hacía incluso referencia a los aspectos éticos que debían considerarse en la explotación ballenera, algo que en el Chile de la época no era un tema de discusión. Señalaba: “...es loable de recordar a los espíritus olvidadizos que la dignidad del hombre es de limitar en la medida de lo posible la matanza a sus necesidades (caza, industria, colecciones)". Liouville, op. cit., 246. La traducción es nuestra.

113 Charcot, op. cit., 47.

114 Ibid., 34.

115 Sociedad Ballenera y Pescadora Valdivia, op. cit., 5.

116 Solo en 1937 los países que practicaban la caza de la ballena subscribieron una serie de medidas reglamentarias, como por ejemplo limitar la temporada de cacería a tres meses y no operar con más de siete catchers por barco-factoría. Ommanney, op . cit., 227. 
Si operamos con un concepto actual de lo que constituye una pesca o caza sustentable, esto es, pescar o cazar sin reducir la biomasa del stock ${ }^{117}$, comprobamos que las perspectivas de Liouville, Charcot y otros se ajustaban al criterio envuelto en dicho concepto. Para Liouville, la forma que tomaba la explotación antártica podría llevar a la desaparición del recurso. A su juicio, de continuar con una caza inescrupulosa, que tomara solo en cuenta el rendimiento económico, pero no considerara la renovación del recurso:

"Se producirá pronto para los cetáceos lo que se produjo en pleno siglo XIX para la foca de piel (Otaria jubata), desaparecida de la Antártica americana; lo que se produjo a comienzos del siglo XX para la garza (Ardea alba) en Indochina; lo que se estaba produciendo para el elefante y la jirafa desde Stanley y hasta nuestros días en el África Oriental inglesa, si los gobernantes no hubieran tomado a tiempo sabias medidas, limitativas que los administradores de otros Estados debieran a su vez imitar"118.

Y eran justamente los adelantos técnicos en materia de cacería -unidos a la abundancia del recurso- los que estaban provocando una cacería poco sustentable, ya que existía una capacidad técnica instalada que hacía posible un alto índice de captura, lo que se conjugaba con la abundancia de la población de cetáceos de la zona antártica y la ausencia de regulación. Se trataba, a juicio del científico francés, de una industria basada en un recurso que de ninguna manera era inagotable y que por el contrario requería de un largo tiempo para regenerarse ${ }^{119}$. Había por lo tanto que situar la cacería de ballena en el largo plazo y analizar la capacidad de renovación del recurso en una mirada de futuro. De primar el criterio comercial por sobre el de la sustentabilidad, el futuro se dibujaba oscuro:

"No son esos los principios económicos de gran sabiduría, y si los valientes pescadores de la pequeña Noruega encuentran en ello un medio de subsistencia que les honra por el valor desplegado, lo menos que puede decirse es que corren el riesgo de arruinar con sus propias manos a la industria que les habrá hecho vivir por tantos años a ellos y a sus antepasados" $" 120$.

Concluía Liouville pronosticando la huida de los cetáceos hacia lugares inaccesibles para los navíos comerciales, lo que sin duda constituiría un acto inédito en la historia de sus migraciones, o bien, que aquellos desaparecerían, como lo enuncia en varios pasajes de su libro. En ese caso: "Será el momento de liquidar las sociedades que habrán gastado sin remuneración el aporte de sus capitales, después de haber tentado a los ojos de los pobres empleados juna fuente imaginaria de prosperidad!" 121 .

117 "Sustainable catch (yield)", en Food and Agriculture Organization of the United Nations (FAO), Fisheries Glossary, http://www.fao.org/fi/glossary/default.asp. Fecha de consulta: 2 de agosto del 2009

118 Liouville, op. cit., 247. La traducción es nuestra.

119 Idem.

120 Liouville, citado por Betancourt, op. cit., 180.

121 Liouville, op. cit., 248. La traducción es nuestra. 
A fines de la década de 1920, parecía que el pronóstico de Liouville se confirmaba en la voz del sacerdote y explorador salesiano Alberto de Agostini. El religioso y viajero italiano había tenido la oportunidad de ver un grupo de cachalotes de cerca en una de sus múltiples expediciones, y a propósito de ello criticaba la cacería realizada por las sociedades balleneras, que a su juicio había diezmado considerablemente la población de cetáceos. En particular sus críticas apuntaban a la Sociedad Ballenera de Magallanes, que según la información de que disponía había llegado a cazar 449 ballenas en el período que se extiende desde julio de 1906 hasta enero de $1908^{122}$.

\section{La soberanía de los territorios antárticos}

La Sociedad Ballenera de Magallanes tuvo un significado destacadísimo en términos de ocupación del territorio antártico, en un período en que las cartografías de territorios como el Polo Sur aún estaban contorneándose y en que existía bastante ambiguiedad respecto de la posesión de islas y territorios en general en la zona austral del mundo. Por eso, para diversos autores que se han referido a la soberanía chilena en la Antártica, la presencia de la Sociedad Ballenera de Magallanes -aunque fuese una mixtura en la que confluían capitanes y marineros noruegos con socios capitalistas en su mayoría inmigrantes- fue una forma trascendente de marcar soberanía chilena en ese territorio. Porque más allá de la confluencia de nacionalidades, la compañía era chilena, aprobada por el Presidente de la República e inscrita en el país. En la década del 40 fue Óscar Pinochet de la Barra quien se refería a la Sociedad Ballenera de Magallanes como un orgullo nacional y "vívido ejemplo de lo que puede la voluntad emprendedora de sus hijos". Para el autor, la explotación ballenera de la sociedad habría marcado definitivamente la ocupación de los mares antárticos y en específico de la isla Decepción. Todavía más, a su juicio, una vez que la sociedad se disolvió, el depósito de carbón dejado en sus antiguas dependencias, habría mantenido la ocupación chilena de la isla. Pinochet de la Barra rescataba el valor que la explotación económica de la zona, en este caso, la ballenera, representó para la afirmación de soberanía del territorio antártico, y no dudaba en elogiar a quienes fueron los protagonistas de la empresa, con palabras como las siguientes: "El extraordinario espíritu de empresa y la capacidad realizadora de los esforzados hijos de Magallanes"123. Un argumento cercano esgrimió sobre el tema Jorge Berguño:

"En 1905 [sic] se realiza la primera campaña antártica de la Sociedad Ballenera de Magallanes en el buque cazador Almirante Montt y, a fines del año siguiente, la flotilla que encabeza Adolfo Andresen [...] entra a la espaciosa bahía de isla Decepción, que las naves de la empresa seguirán visitando hasta 1915. La epopeya ballenera constituye una presencia nacional significativa que, en cierta medida, contribuye a detonar el litigio internacional antártico [...] y que las autoridades navales consideraban suficientemente importante para proponer la ocupación de las islas Shetland, como lo hacía el Coman-

122 Alberto de Agostini, Mis viajes a la Tierra del Fuego, Milán, G. De Agostini, 1929, 105.

123 Óscar Pinochet de la Barra, La Antártica Chilena, Santiago, Editorial Andrés Bello, 1976, 95. 
dante del Apostadero Naval de Magallanes, Contralmirante Pedro Nolasco Martínez, en oficio de noviembre de 1911"124.

Alfonso M. Filippi coincidió con Berguño, señalando que las acciones de Andresen "son de gran trascendencia para Chile, especialmente por su importancia geopolítica y por la reafirmación de soberanía que implican" ${ }^{125}$. Por su parte Jaime Eyzaguirre utilizaba también el vocablo "soberanía" al referirse a la decisión de los balleneros de la sociedad de instalarse en Decepción, tras un permiso del gobernador de Magallanes ${ }^{126}$. Mateo Martinic se suma a los autores anteriores, señalando que la empresa de Andresen quedaría registrada en los anales marítimos de Chile, al afirmar los derechos nacionales en el territorio antártico ${ }^{127}$.

El período ciertamente está cruzado por expediciones exploratorias al extremo austral que tenían como finalidad descubrir ensenadas, islas, cuencas y estrechos, en fin, ir definiendo con mayor exactitud los contornos de estos territorios poco conocidos. Es sorprendente comprobar cómo los capitanes de las flotas balleneras se lanzaban a los mares antárticos sin contar con mapas exactos, precisamente porque aún había mucho por descubrir en el plano territorial, en el de los fenómenos climáticos y en el de las especies naturales y animales que poblaban la zona. La expedición de Charcot tenía precisamente ese objetivo. Comentaba el viajero cómo otras expediciones anteriores a la suya habían sido de gran beneficio para los cazadores de ballenas, ya que se les había podido proporcionar, como resultado de ellas,

"la carta de la costa N.W. del archipiélago de Palmer, que antes no existía, la del estuario de Bismarck, indicándoles el excelente anclaje del puerto Lockroy y un abrigo eventual en la isla Wandell, sin contar datos acerca del número y especies de balenópteros, movimientos de los hielos, vientos reinantes, etc." 128 .

Llama la atención en particular que la soberanía de las islas Shetland del Sur, donde se situó la base de operaciones de la Sociedad Ballenera de Magallanes, no estuviera clara en el período, reclamándolas al menos tres países como suyas. Así, la Sociedad Ballenera de Magallanes obtuvo del gobernador de Magallanes la autorización para habilitar una base y depósitos en las islas, según el Decreto 1314 del 1 de diciembre de $1906^{129}$. No obstante, años más tarde la situación había cambiado, siendo la pretensión británica abarcar la soberanía de estas islas, ya ocupadas por compañías balleneras tanto noruegas como la chilena. En el año 1909, los balleneros chilenos debían pagar una patente para poder realizar la caza de ballenas en las islas, que estaban bajo la jurisdicción de las Malvinas. Sin embargo el periódico de Punta Arenas, Chile Austral, se preguntaba en marzo de 1909: "Las

124 Jorge Berguño, "La primera expedición antártica oficial de Chile", en Boletín Antártico Chileno 2, Santiago, 2007, 16.

125 Filippi, op. cit., 1.

126 Eyzaguirre, op. cit., 51.

127 Martinic, Historia..., op. cit., 829.

128 Charcot, op. cit., 43.

129 Martinic, "Actividad lobera...", op . cit., 17. 
Islas Shetland ¿pertenecen a Chile?” e ingenuamente el autor del artículo indagaba en la enciclopedia Británica de New Berner, donde descubría que para los británicos las Islas Shetland les pertenecían, al ser nuevamente descubiertas por el capitán inglés William Smith en el año $1819^{130}$. Días más tarde, el mismo periódico hacía alusión a la "ocupación temporal" de las islas en cuestión, agregando:

“Aunque el gobernador de las Malvinas tenga el Pomposo título de 'Gobernador Of the Falkland, South Georgia, South Shetland and adjacent islands' creemos seria materia de estudio para nuestras Autoridades, el profundizar si esas contribuciones i licencias, i aun el dominio mismo de las islas, es correcto"131.

Por su parte las compañías noruegas no habían consultado al gobernador de Magallanes para la instalación de sus buques y plantas en la isla Decepción, sino que lo habían hecho al gobernador de las islas Malvinas, y una serie de roces entre las compañías noruegas y la Sociedad Ballenera de Magallanes, todas apostadas en la bahía de la isla, habían comenzado a surgir a partir de 1908, relacionados con la cuestión de la ocupación, permisos de explotación y arrendamiento ${ }^{132}$.

A juicio de Liouville una de las razones de por qué la Sociedad Ballenera de Magallanes probablemente no levantó una usina en Decepción, decía relación con el peligro que podía representar en el futuro una instalación de este tipo, toda vez que los británicos pudieran llegar a exigir un pago tributario, en razón de su reclamo de las Shetland del Sur ${ }^{133}$.

Para Argentina, por su parte, la ocupación de Malvinas por parte de la Corona Británica, si bien, aceptada de facto, también era cuestionada, sobre todo en relación al cobro de un impuesto por explotación de la cacería de ballenas, que era a su modo una clara señal de dominio de las islas en cuestión ${ }^{134}$.

Por lo tanto, la Sociedad Ballenera de Magallanes había contribuido sin proponérselo a marcar soberanía en las tierras antárticas, lo cual para algunos autores tenía connotaciones de gesta heroica. Cordovez Madariaga, por ejemplo, consideraba en la década de los 40 que la cuestión de la soberanía chilena en la Antártica no era un tema reducible a los elementos jurídicos, ya que existía una ocupación de facto protagonizada por los hombres de mar chilenos, que no eran otros que los cazadores de lobos marinos y más tarde los cazadores de ballenas. Su prosa destaca la grandeza de estos hombres en contraposición a las hostilidades del medio en que debían desenvolverse. La ganancia económica implícita en las aventuras de cacerías marinas en los mares gélidos de la Antártica no calificaba como factor atenuante de la heroicidad de estos hombres. Leamos al propio Cordovez Madariaga, quien se refirió al derecho soberano que limita el territorio antártico nacional:

\footnotetext{
130 Chile Austral, 17 de marzo de 1909, 9.

131 Idem, 19 de marzo de 1909, 6.

132 Martinic, "Actividad lobera...", op . cit., 19

133 Liouville, op. cit., 185.

134 Chile Austral, 21 de marzo de 1909, 6.
} 


\begin{abstract}
"Derecho soberano por el cual Chile ha pagado tributo con la sangre de muchos de sus hombres de mar; esos diestros cazadores de focas, ballenas y otras especies marinas, que han aventurado sus frágiles embarcaciones hacia las costas antárticas sin que jamás les arredrara el cruce del Mar de Drake, ni los desorientaran los cegadores 'blizzards' que soplan a veces, incesantes durante quince y más días [...].

Son legendarios los actos de heroísmo y sacrificios de tantos y tantos hombres de mar de nuestras aguas australes que han perecido buscando aventuras, nombre y riqueza, adentrándose en el propio Continente Antártico, sin más instrumental que su propio empuje, jugándose la vida a cada instante, sin que lograra detenerlos el hielo sobre el mar que a veces hace inaccesibles las costas por espacio de ochenta y más kilómetros, ni los témpanos que se deslizan silenciosos, fantasmales, en las sombras"135.
\end{abstract}

¿Fueron los cazadores de ballenas antárticas "héroes del mar”? De ello trata el siguiente subcapítulo.

\title{
¿Aventura heroica?
}

La legislación que velaba sobre la protección de la ballena, buscando racionalizar su caza y por lo tanto hacerla sustentable, comenzó en la década de los trein$\mathrm{ta}^{136}$. Más tardías aún, salvo las excepciones mencionadas, fueron las voces que se alzaron para denunciar la crueldad de la cacería e intentar ya no regularla, sino lisa y llanamente suprimirla, arguyendo entre otros argumentos, el peligro de extinción en que se encontraban los cetáceos. Nada de ello ocurría en los inicios del siglo XX. Por el contrario, la actividad ballenera -sobre todo en las zonas antárticas- era considerada por los contemporáneos como una suerte de gesta heroica, que además de la conveniencia geopolítica que significaba para el país y del desarrollo económico regional, hablaba de las habilidades y valentía de quienes las protagonizaban.

En el Diccionario de la Real Academia Española, una de las acepciones de la palabra "héroe" dice: "varón ilustre y famoso por sus hazañas o virtudes"137. Las condiciones climáticas adversas y el tipo de acción que se realizaba demandaban, sin lugar a dudas, a los capitanes de los barcos balleneros y su tripulación ciertas capacidades, tanto físicas como emocionales, para desenvolverse en un ambiente de ese tipo. ¿Pero era realmente una hazaña heroica la cacería de la ballena en las zonas antárticas a principios del siglo XX?

135 Cordovez Madariga, op. cit., 19-20.

136 En 1930 tuvo lugar una conferencia convocada por la Liga de las Naciones que acordó una primera regulación en la materia, pero en la cual no todos los países que practicaban la cacería participaron. A ella siguió el acuerdo celebrado en Londres en el año 1937 -mencionado antes- que, no obstante algunos puntos positivos, no regulaba el número de ballenas cazadas permitidas. En 1944, otra conferencia realizada en Londres logró acuerdo sobre este aspecto trascendental, fijándose el número de ballenas que se permitía capturar en la Antártica. En el año 1949 se creó la Comisión Ballenera Internacional, que tuvo como misión primordial "resguardar los stocks de ballenas". José B. Pavisic, Antecedentes para una política ballenera antártica, Memoria de Prueba para optar al grado de Licenciado en Ciencias Jurídicas y Sociales de la Universidad de Chile, Santiago, Editorial Universitaria, 1955, 67 y 68 .

137 Diccionario de la Lengua Española, 22ª edición, Madrid, Real Academia Española, 2001. 
Veamos en primer lugar algunas impresiones sobre las condiciones de vida de los avezados marinos, en su mayoría noruegos o de otros países extranjeros, que se dedicaban a la actividad. Vivir en la base de operaciones de la isla Decepción en la temporada de verano no debe haber sido del todo inhóspito, al menos para los capitanes de los navíos balleneros y en particular para los de la Sociedad Ballenera de Magallanes, que por diversas fuentes sabemos que contaban con la mejor flota de la zona, entre todas las que se dedicaban a la cacería de la ballena en la Antártica. Sabemos que existían cuatro compañías y alrededor de 200 hombres. Solo una mujer, la esposa de Andresen, vivía en estos helados territorios en los meses que duraba la cacería antártica, como comenta Charcot en su diario: la única y primera mujer hasta ese entonces que habitaba en la Antártica.

Los barcos, no obstante, estaban muy bien acondicionados, eran hasta cómodos. Charcot tuvo la oportunidad de visitar algunos de ellos, tanto de la Sociedad Ballenera de Magallanes como de las compañías noruegas. El ballenero noruego Ravn, por ejemplo, era a juicio del científico francés “[...] no obstante el ejercicio a que se entrega, sorprendentemente limpio", y agregaba que su capitán lo había conducido:

“[...] a un saloncito confortable y casi elegante, donde arde en una estufa un lindo fuego de carbón. Pasamos enseguida al mayor de los vapores, el Gobernador Bories [...] y me introducen en un salón grande, extremadamente limpio, hasta lujosamente decorado. Un loro, que debe estar muy fuera de su país en el Antártico charla gravemente, y allí también hay un buen fuego en la estufa. Como en el Raun [sic], lo contemplo con un poco de envidia, pues que a bordo del Pourquoi Pas? a fin de economizar todo el carbón, no encendemos fuego y padecemos humedad [...]"138.

Más adelante en su diario, Charcot comentaba que el Almirante Uribe, una de las más recientes adquisiciones de la Sociedad Ballenera de Magallanes, "para gentes que amen verdaderamente el mar constituiría un verdadero yatecito"139.

Para la tripulación, la vida no era hostil pero tampoco fácil. Su trabajo requería de una combinación de fortaleza, dinamismo y disciplina. Así, por ejemplo, las bebidas alcohólicas estaban prohibidas durante las campañas de trabajo. Si bien existía una cantina a disposición de la tripulación de los navíos, esta no ofrecía alcohol, el cual se subía a bordo solo para ser servido en ocasiones especiales, por ejemplo, cuando se contaba con la presencia de visitantes ${ }^{140}$. La tripulación por lo tanto se contentaba con beber agua, té y ocasionalmente café, siendo la leche concentrada una verdadera golosina. Respecto a la alimentación, comentaba

138 Charcot, op. cit., 35.

139 Ibid., 369.

140 Liouville recordaba que en su visita a los barcos balleneros en la expedición de Charcot, los comandantes no vacilaron en invitarlos a brindar con ellos. Tenían, para ocasiones como esas, ponche sueco, cerveza, aguardiente de Trondjen y arak. Recuerda también Liouville que pasó una noche de navidad en compañía de los comandantes balleneros -Charcot también lo mencionó en su diario de viaje- y si bien todos los navíos estaban de fiesta, no había signo de embriaguez alguno. Liouville, op. cit., 216. 
Liouville: "El marino noruego se somete a cualquier régimen alimenticio, sin murmurar, con un valor y una alegría que les hacen el más grande honor"141.

Sin embargo, había limitaciones de otro tipo. Si consideramos en primer lugar las condiciones climáticas en que la cacería se llevaba a cabo, comprobamos que efectivamente estas a menudo eran del todo desfavorables. Charcot ha dejado registrado en su diario de viaje algunas descripciones de la rudeza del clima antártico. Escribió con fecha 29 de noviembre de 1909, habiendo entrado en contacto con la Sociedad Ballenera de Magallanes:

\begin{abstract}
"Durante toda la mañana he temido derivar, porque aquí no se puede anclar sino a grandes profundidades y la permanencia es mala; los balleneros me han prevenido de otra parte que es preciso tener cuidado, pues a pesar de todas las precauciones de que ellos se rodean, y que nosotros no podemos tomar, a causa de nuestra corta estancia, me dicen que con frecuencia son arrojados a tierra. [...] a las seis y media, a pesar del tiempo cerrado (hay tormenta de nieve) el Svenfoyn, otro buque fábrica, acompañado de sus pequeños balleneros, llega a la rada y ancla junto a nosotros. Decididamente hay que reconocer que estos noruegos son los mejores marinos. Todos los balleneros están fuera, cazando; hasta uno de ellos ha traído a remolque dos ballenas, y se ha vuelto a marchar sin tardanza"142.
\end{abstract}

Charcot agregaba comentarios tales como "por la tarde el tiempo ha sido horroroso" o "la mar es tan gruesa que no podemos salir en embarcación". El día 2 de diciembre, dejó registrado en su diario: "El hielo del fondo de la bahía invade el paso en grandes témpanos y cierra la mayor parte de la ensenada de los Balleneros. Así los barcos pequeños entran y salen con enormes dificultades"143. No parece, sin embargo, que las condiciones climáticas menguaran los ímpetus -al menos del capitán Andresen así como del conjunto de su tripulación-. La cacería se llevaba a cabo bajo las condiciones climáticas que hubiera e incluso el capitán noruego se arriesgaba a realizar empresas osadas, como el rescate del Telefon.

Sin duda la navegación en los mares australes planteaba sus serios desafíos. Carlos Aramayo Alzérreca, en su "Breve Historia de la Antártica", dedicó páginas precisamente a la descripción de las desventajosas condiciones climáticas de la región polar antártica y de cómo los navegantes en distintas épocas las desafiaron movidos por el interés económico o el de la exploración. Así por ejemplo, hacía alusión a los huracanes antárticos, "que rugen endemoniadamente durante semanas enteras", o a los icebergs como peligros para quienes navegaban estos mares, a los fuertes vientos y a la espesa neblina que podía llegar a ocultar el paisaje por completo, como si fuera una suerte de "nieve hecha humo"144. Ernesto Greve nos permitió acercarnos a los peligros de la navegación antártica, al hablar de los pack ice -los hielos flotantes que se forman en los mares polares- y relató cómo el

141 Idem.

142 Charcot, op. cit., 359.

143 Ibid., 360.

144 Véase Carlos Aramayo Alzérreca, Breve Historia de la Antártica, Santiago, Editorial ZigZag, 1963 . 
experimentado capitán ballenero Carl. A. Larsen “demoró siete días -en los años '20- en cruzar el pack, en constante peligro para su escuadrilla, habiendo sido apresado por el hielo uno de sus cazadores durante otros seis"145.

Óscar Pinochet de la Barra, cautivado por los paisajes que en diversas ocasiones pudo contemplar en el continente helado, también habló de la ferocidad del clima, que de un momento a otro podía pasar de la apacibilidad y la calma a la tormenta. Si bien el autor estaba hablando de un viaje que tuvo lugar años después de los eventos que relatamos, es posible pensar que una situación similar podrían haber experimentado los balleneros a principios del siglo XX. En sus palabras:

"Recordamos las sesenta horas de temporal, pasadas en Puerto Covadonga junto a la base O’Higgins, en febrero de 1948. Sesenta horas en la que el viento sopló a más de 100 kilómetros por hora, haciendo privar con lastimeros tonos todas las cuerdas de nuestro buque, y pasando de los suaves silbidos de súplica y encantamiento al endemoniado crujir de toda la obra muerta de la 'Covadonga'. El viento polar tiene vida real y se lo veía venir de las altas montañas de hielo que jamás nadie ha visitado [...]"146.

A las condiciones climáticas debe sumarse el hecho de que las compañías en isla Decepción, o bien a bordo de los buques navieros, no contaban con médicos y los accidentes parecían frecuentes, dado que si bien se tomaban medidas precautorias, el riesgo estaba siempre presente. De hecho, todo indica que en Decepción en su conjunto no existía sino un médico en 1910, que era pagado por todas las compañías establecidas en la isla ${ }^{147}$. Acciones, por otro lado, un tanto extremas se hacían con tal de lograr los objetivos deseados. Por ejemplo, Charcot, bien aprovisionado, al menos en lo que a capital humano se refiere, sí contaba con médicos en su tripulación (él mismo lo era) y puso al servicio de Andresen a uno de ellos -Liouville-, en momentos en que uno de sus hombre sufrió un serio accidente. Como dejó estampado en su diario:

"Pregunto por mi parte, a M. Andresen si puedo serle de alguna utilidad; me dice entonces que su señora [...] está algo enferma, y que uno de los operarios de a bordo, cortador de ballenas, acaba de ser víctima de un grave accidente. En la estación no hay médico, y el herido acaba de regresar de la bahía del Almirantazgo, en donde había creído encontrar alguno, aunque en vano [...] en seguida con Liouville, examinamos a la señora Andresen, cuya indisposición, afortunadamente, carece de importancia. No ocurre lo propio con el herido: el desdichado tiene cuatro dedos cortados a bisel por una cuchilla a vapor, siendo preciso hacerle la amputación de los mismos para salvarle, no solo la mano, sino muy probablemente la vida. Liouville le hace una cura provisional, pero está decidido a volver mañana para practicarle la operación"148.

145 Ernesto Greve, La vida marina en su relación con la pesca y la caza, Santiago, Imprenta Universitaria, 1949, 77.

146 Pinochet de la Barra, op. cit., 192.

147 Betancourt, op. cit., 181.

148 Charcot., op. cit., 46. 
Liouville cumplió su palabra, la operación fue practicada y un año más tarde, al reencontrarse Charcot con los balleneros, tuvo la buena noticia de que la operación había sido un éxito y el operario estaba totalmente restablecido. Charcot reflexionaba, en aquellos momentos del verano de 1908, que de no haberlo operado probablemente el accidentado hubiese perdido la vida, ya que la gangrena hubiese invadido su cuerpo. Si bien Andresen había tomado la decisión de enviarlo a Punta Arenas, para el médico francés hubiese sido demasiado tarde ${ }^{149}$. Los accidentes no eran poco frecuentes, ya que en el breve período en que Charcot estuvo en isla Decepción en contacto con Andresen y sus hombres, uno de sus marineros también sufrió un accidente de cierta gravedad, que terminó en una herida del pie que a juicio de Charcot necesitaba intervención quirúrgica.

Por otro lado, el abastecimiento de agua dulce y de alimentos necesarios para una dieta saludable no siempre eran fáciles. Los manantiales existentes de agua caliente, al ser sulfurosos, no podían utilizarse. La Sociedad Ballenera de Magallanes había ideado un método para captar el agua proveniente de las pequeñas cascadas que se formaban al derretirse la nieve del acantilado situado en la entrada de la ensenada. Pero si las temperaturas eran muy bajas, la nieve se derretía escasamente y solo en algunos momentos del día. En ocasiones, los balleneros de la sociedad acudían a un glaciar fósil alejado de la isla para obtener el preciado elemento, transportado en barcos-cisternas remolcados por "canoas-automóviles". Pero la tarea no era fácil: si bien la sociedad era muy bien catalogada en la época por la calidad de su flota, algunos aspectos del diario vivir parecían solucionarse más con el ingenio y rudimentarios materiales que con modernos procedimientos semejantes a los aplicados para la cacería de los cetáceos. Así por ejemplo, para procurarse agua, los balleneros "llevan [...] todo un material de mangas de tela, tubos de fundición, tablas para hacer caces y barricas agujereadas" 150 . Ni siquiera la indumentaria adecuada parecía estar siempre presente, como ocurrió cuando un buzo de la tripulación de Andresen procuraba abastecer de agua dulce al Pourquoi-Pas? El capitán del Telefon le había cortado un par de guantes de cuero, pero las costuras no los hacían totalmente impermeables, de modo que el mencionado buzo solo podía estar bajo el agua algunos minutos. Solo una vez que Charcot le obsequió unos tubos de caucho líquido que encontró en su navío pudo repararse el problema, y "este regalo, insignificante en apariencia, llega a ser inapreciable para el trabajo de nuestros amigos"151.

Por otro lado, vivir en la Terrae Australis, sin demasiado contacto con otra gente que no fuera la que componía las cuatro compañías con base en isla Decepción, provocó el desarrollo de prácticas solidarias que buscaban enfrentar las adversidades de las condiciones en las que se vivía y desarrollar lazos de sociabilidad, toda vez que la oportunidad se diera. Charcot nos relató cómo al ir entrando a la cuenca central que los condujo a la isla Decepción, la tripulación del

\footnotetext{
149 Ibid., 49.

150 Ibid., 363.

151 Ibid., 363-364.
} 
Ravn lanzó hurras en su honor y su capitán le ofreció guiarlos a la isla, pese a que no estaban volviendo a ella, sino recién partiendo a su recorrido por las zonas de cacería.

"Aunque previsto -comentaba Charcot- por los que ya habíamos estado en el Antártico
en 1904 , en que sabíamos ser entonces los únicos seres humanos, el encuentro de
buques en esta región, tranquilamente dedicados a su trabajo, tenía algo de emocionante
y casi de inquietante, y esta sensación iba a ser más fuerte todavía cuando nos encontrá-
semos en la cuenca de Decepción [...]" 152 .

Una vez que estableció contacto con Andresen, y llevando una carta de los directores de la sociedad desde Punta Arenas para tal propósito, Charcot fue abastecido de cargamentos de carbón. A cambio de este abastecimiento, Andresen solo pidió que la misma cantidad le fuera restablecida en algún viaje a Punta Arenas de la reserva del Pourquoi-Pas?, ante lo cual Charcot quedó sorprendido:

"[...] porque hubiese sido muy natural que me hiciese pagar el carbón a un precio muy elevado; y dadas las condiciones en que nos encontrábamos, creo que hubiese pasado por todas las exigencias. Me ofrece también petróleo que nos falta, y por la tarde me envía un estimable regalo de dos sacos de patata [...]

Pero a pesar de la concurrencia entre las diferentes Compañías, directores, capitanes y tripulaciones, lejos de tratar de dañarse unos a otros, se ayudan en todo, y particularmente en la cuestión del agua; los trabajos de los unos y de los otros sirven para todos" $" 153$.

Los capitanes de los navíos de la Sociedad Ballenera, hasta donde sabemos de nacionalidad noruega, eran marineros fogueados en las lides del mar. De Andresen, sobre quien más antecedentes se disponen, se ha señalado que contaba con una experiencia que se remontaba a su tierra natal, Noruega. Sin duda la cacería de ballenas representaba para él, más que un medio de ganarse la vida e incluso hacer fortuna, una opción de vida ligada al mar y a los diversos desafíos que la cacería en las tierras australes suponía.

Podemos concluir que la vida cotidiana en isla Decepción no era del todo inhóspita para los capitanes de los buques balleneros, aunque sí un poco más para la tripulación. Inferimos, en otro frente, que cazar ballenas en las regiones antárticas representaba ciertas complicaciones y desafíos ocasionados por las condiciones climáticas en la zona. Entonces, ¿es pertinente hablar de hazaña, cuando nos referimos a la actividad de cacería en los mares australes?

Pensamos que para el imaginario de la época la actividad ballenera estaba revestida de prestigio. Se consideraba a sus hombres valientes marinos avezados

152 Ibid., 34 .

153 Ibid., 358, 359 y 363. Ello, no obstante, debe matizarse con la afirmación hecha por Martinic sobre las diferencias o roces que se habrían producido entre la Sociedad Ballenera de Magallanes y las sociedades noruegas operando en Decepción, con motivo de la ocupación de la isla. Véase Martinic, “Actividad lobera...", op . cit., 19. 
en la práctica en cuestión, valerosos hombres que no trepidaban en lanzarse a los mares australes en busca de su objetivo. Se hablaba en estos casos, por supuesto, de los capitanes y su tripulación, no de los accionistas o socios capitalistas que cómodos en sus hogares o despachos no conocían de tormentas, de la hediondez proveniente de los cetáceos muertos ni de los variados sinsabores asociados a la explotación ballenera. Los propios noruegos cultivaban este prestigio que rodeaba su actividad, recurriendo a su vastísima y bien conocida tradición ballenera. Para Liouville, que los conoció de cerca, en un primer momento los "héroes polares" -como él los denominaba- mostraban una mezcla de falsa rudeza, ingenua vanidad y elegancia un poco afectada, pero luego era posible apreciar las cualidades positivas de estos marinos nórdicos:

“[...] un patriotismo muy sincero, un verdadero sentido del mar, una indiscutible valentía, un entusiasmo por el trabajo ejemplar, una fuerza física bien cultivada y siempre dispuesta a la acción, un respeto natural por la disciplina mezclado con una gran independencia de espíritu" ${ }^{154}$.

Por otro lado, la actividad ballenera de principios del siglo XX estaba revestida de prestigio, sobre todo en los momentos de mayor esplendor de la Sociedad Ballenera de Magallanes, porque de alguna manera actuaba como acicate para el desarrollo y el progreso de la región. Punta Arenas era, en tanto puerto y principal ciudad de la zona en el país, el centro de la actividad comercial, con una Bolsa de Valores funcionando, con casas armadoras, con entradas y salidas de buques desde y hacia Europa, en fin con todo un movimiento económico y comercial que no provenía mayoritariamente de la explotación ballenera, pero que sin dudas era alimentado por ella.

Pero lo que es más importante, y creemos que de ahí su estrecha conexión con la heroicidad, es que la acción de estos hombres de mar permitió marcar presencia chilena en territorios cuya soberanía se discutía por aquella época-como las Shetland del Sur-, cuando los mapas antárticos estaban contorneándose y no existía claridad sobre el dominio territorial. No fue este un objetivo propuesto por los creadores de la Sociedad Ballenera de Magallanes, ni por sus socios capitalistas ni mucho menos por sus capitanes de origen extranjero, pero ha sido uno de los elementos que han permanecido con más fuerza en la historia de la sociedad. Mucho de este imaginario de heroicidad ha sido potenciado por autores no contemporáneos a los hechos -como se ha visto en el desarrollo de este artículo-, que han puesto el acento en las virtudes más que en las debilidades. De ahí, por ejemplo, que salvo los diarios o escritos de algunos exploradores extranjeros -Charcot, Liouville y Ommanney-, la gran mayoría de las fuentes de la época y de la bibliografía sobre el tema no mencionen o ahonden en la cuestión de la cacería sustentable. Tal vez sea el epígrafe escrito en la tumba que alberga los restos del Capitán Andresen el que mejor sintetice la visión heroica que ha

154 Liouville, op. cit., 215. 
quedado en el imaginario colectivo de la región sobre los hombres de la Sociedad Ballenera de Magallanes:

“Al Capitán Adolfo Andresen, 1863-1940

Que hizo flamear en la isla Decepción la bandera chilena en señal de soberanía afianzando los derechos de Chile a la Antártica, prolongación histórica y geográfica de la República.

¡Honor a su memoria!

Punta Arenas, 1 Noviembre- 1949”. 